\title{
Technique Development for Modulus, Microcracking, Hermeticity, and Coating Evaluation Capability for Characterization of SiC/SiC Tubes
}

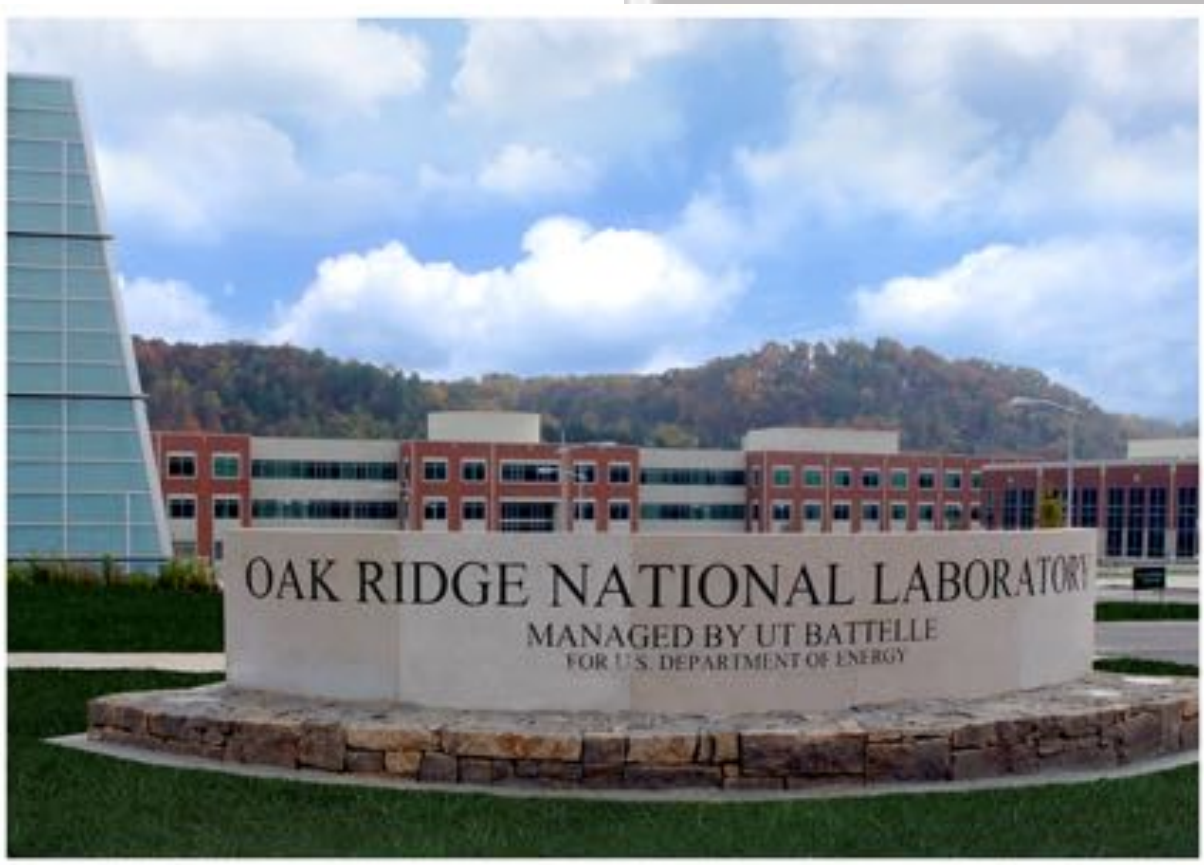

Approved for public release. Distribution is unlimited.
Xunxiang $\mathrm{Hu}$

Caen K. Ang Gyanender P. Singh Yutai Katoh

August 2016 


\title{
DOCUMENT AVAILABILITY
}

Reports produced after January 1, 1996, are generally available free via US Department of Energy (DOE) SciTech Connect.

Website http://www.osti.gov/scitech/

Reports produced before January 1, 1996, may be purchased by members of the public from the following source:

\author{
National Technical Information Service \\ 5285 Port Royal Road \\ Springfield, VA 22161 \\ Telephone 703-605-6000 (1-800-553-6847) \\ TDD 703-487-4639 \\ Fax 703-605-6900 \\ E-mail info@ntis.gov \\ Website http://www.ntis.gov/help/ordermethods.aspx
}

Reports are available to DOE employees, DOE contractors, Energy Technology Data Exchange representatives, and International Nuclear Information System representatives from the following source:

Office of Scientific and Technical Information

PO Box 62

Oak Ridge, TN 37831

Telephone 865-576-8401

Fax 865-576-5728

E-mail reports@osti.gov

Website http://www.osti.gov/contact.html

This report was prepared as an account of work sponsored by an agency of the United States Government. Neither the United States Government nor any agency thereof, nor any of their employees, makes any warranty, express or implied, or assumes any legal liability or responsibility for the accuracy, completeness, or usefulness of any information, apparatus, product, or process disclosed, or represents that its use would not infringe privately owned rights. Reference herein to any specific commercial product, process, or service by trade name, trademark, manufacturer, or otherwise, does not necessarily constitute or imply its endorsement, recommendation, or favoring by the United States Government or any agency thereof. The views and opinions of authors expressed herein do not necessarily state or reflect those of the United States Government or any agency thereof. 
Fuel Cycle Research and Development

\title{
TECHNIQUE DEVELOPMENT FOR MODULUS, MICROCRACKING, HERMETICITY, AND COATING EVALUATION CAPABILITY FOR CHARACTERIZATION OF SIC/SIC TUBES
}

\author{
Xunxiang Hu, Caen K. Ang, Gyanender P. Singh, Yutai Katoh
}

Date Published: August 2016

Prepared by

OAK RIDGE NATIONAL LABORATORY

Oak Ridge, TN 37831-6283

managed by

UT-BATTELLE, LLC

for the

US DEPARTMENT OF ENERGY

under contract DE-AC05-00OR22725 



\section{CONTENTS}

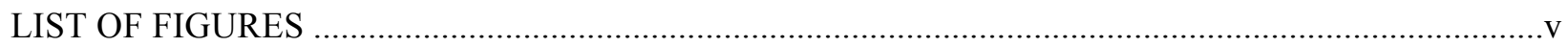

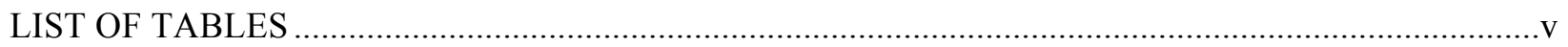

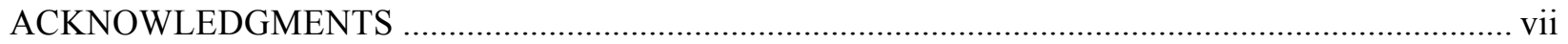

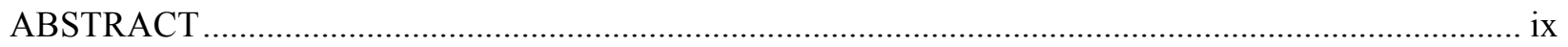

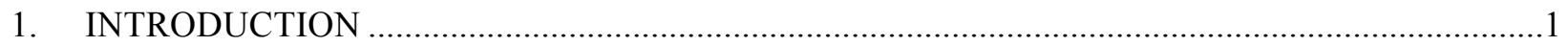

2. EVALUATION OF ELASTIC PROPERTIES OF SIC/SIC COMPOSITE TUBES .........................2

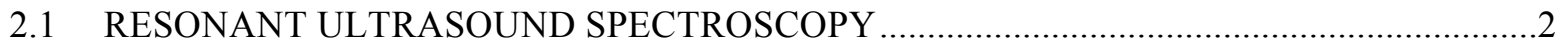

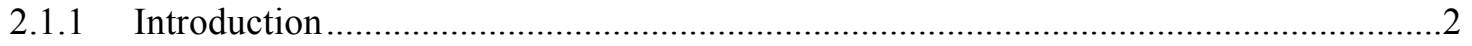

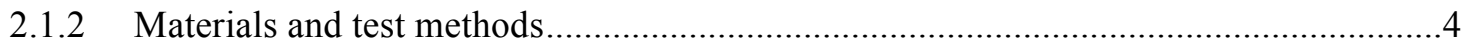

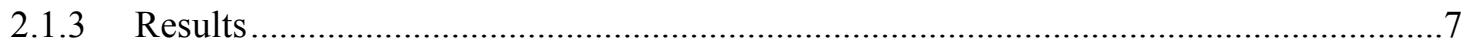

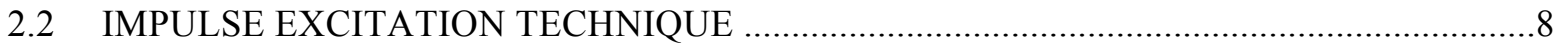

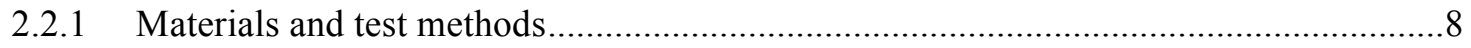

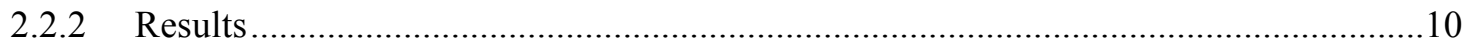

2.3 CORRELATION BETWEEN YOUNG'S MODULUS AND MICROCRACKING ...............10

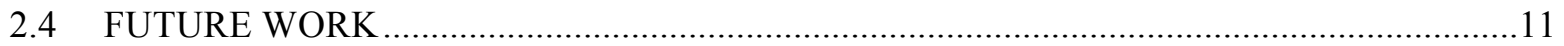

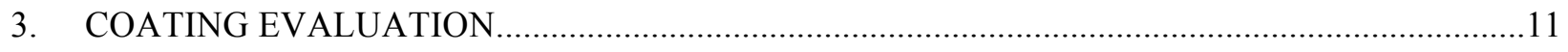

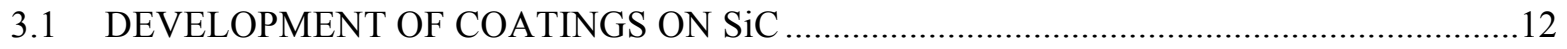

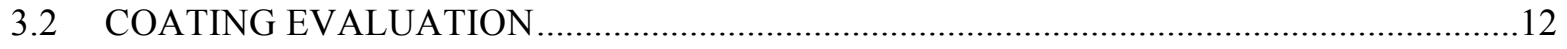

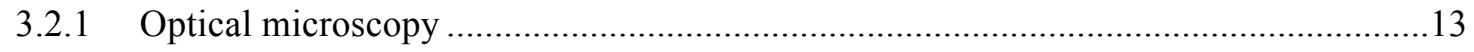

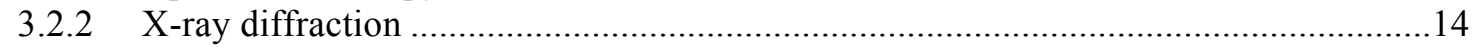

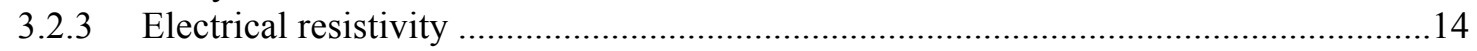

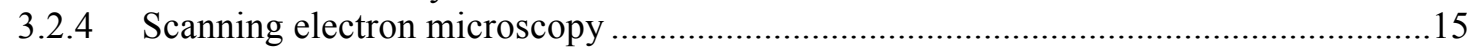

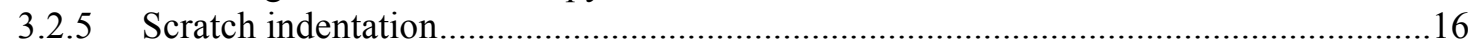

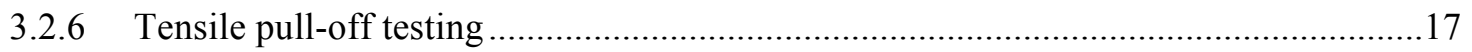

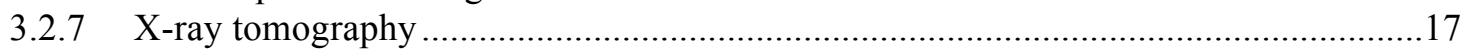

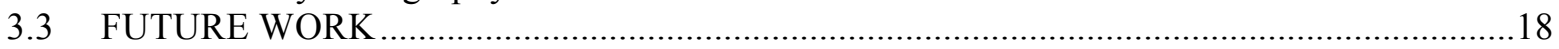

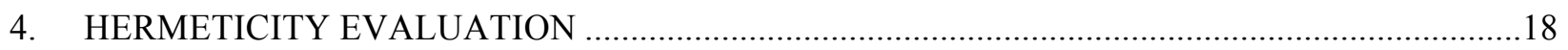

4.1 DEFINITION OF PERMEABILITY ......................................................................... 18

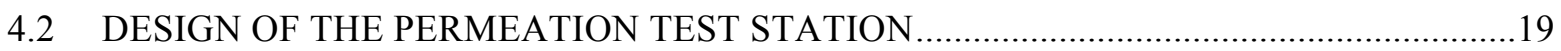

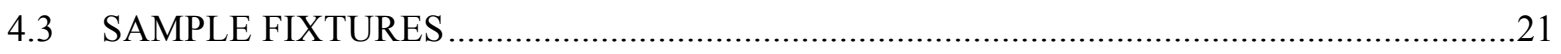

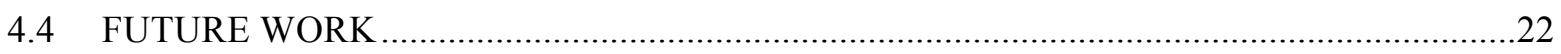

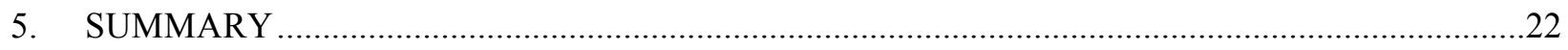

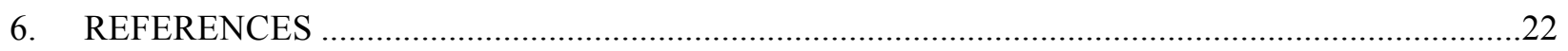





\section{LIST OF FIGURES}

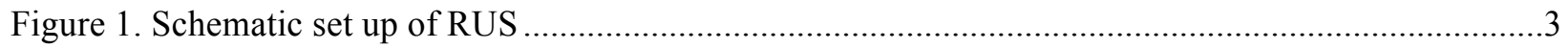

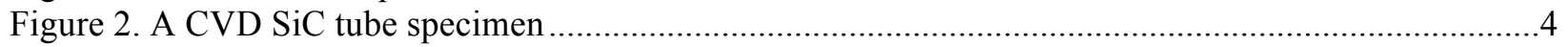

Figure 3. Specimen placed on the RUS transducers to obtain the spectrum (left) ..................................5

Figure 4. Finite element model of tube specimen for determining the resonance frequencies

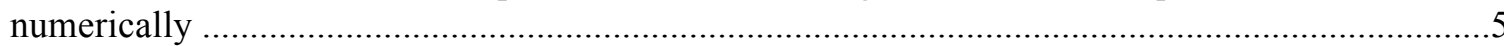

Figure 5. Numerically obtained vibration modes for a CVD SiC tube specimen.....................................6

Figure 6 . The cumulative difference between the numerically obtained frequencies and the frequencies obtained through RUS is denoted on the chart as "Error." .........................................

Figure 7. Schematic plot of the setup for the impulse excitation technique to determine the elastic

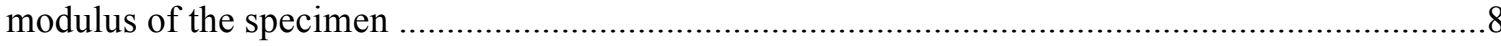

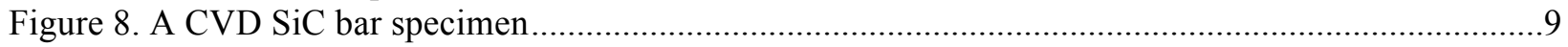

Figure 9. SiC bar specimen tested by the impulse excitation technique …............................................9

Figure 10. Signal for a specimen after conversion from acoustic to electric (left) .................................10

Figure 11. Stress-strain curve (left) and the corresponding acoustic emission signals (right) for a

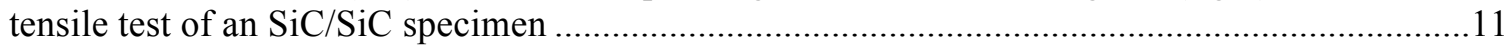

Figure 12. Two examples of braid-topologies with which a coating may interact...................................13

Figure 13. Main image showing the side of a $\mathrm{SiC} / \mathrm{SiC}$ tube at $30 \times$ (with an end-view shown in the inset on the lower left)

Figure 14. Polished cross-section of a coated SiC sample (a) that shows good interface bonding between the Ni-Cr coating and the substrate compared with (b) a coating that shows a

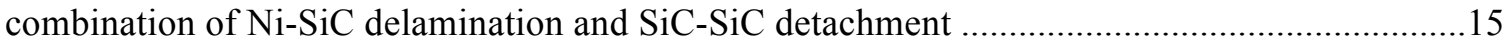

Figure 15. Cross-section of coated SiC sample after ASTM E2546 scratch indentation testing ................16

Figure 16. (a) Positest AT-M in compliance with ASTM D4541 adhesion pull-off test. ........................17

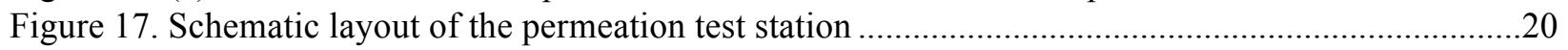

Figure 18. Planar sample fixture used in the permeation test station ...................................................21

Figure 19. Schematic plot of the tubular specimen used in the permeation test station ............................22

\section{LIST OF TABLES}

Table 1. Young's modulus values for CVD SiC tubular specimens evaluated using RUS ….....................7

Table 2. Young's modulus values for the specimens evaluated using impulse excitation .........................10

Table 3. Major technical specifications of the permeation test station ..................................................20 



\section{ACKNOWLEDGMENTS}

The authors would like to thank Aaron Selby, Shawn Reeves, and Jim Kiggans for technical support, and Takaaki Koyanagi for critical review of the report. Research was conducted at the High Temperature Materials Laboratory and the Low Activation Materials Development and Analysis facility at Oak Ridge National Laboratory. The research is sponsored by the Advanced Fuels Campaign of the Fuel Cycle R\&D program, Office of Nuclear Energy, US Department of Energy, under contract DE-AC05- 00OR22725 with UT-Battelle, LLC. 



\begin{abstract}
Driven by the need to enlarge the safety margins of nuclear fission reactors in accident scenarios, research and development of accident-tolerant fuel has become an important topic in the nuclear engineering and materials community. A continuous-fiber $\mathrm{SiC} / \mathrm{SiC}$ composite is under consideration as a replacement for traditional zirconium alloy cladding owing to its high-temperature stability, chemical inertness, and exceptional irradiation resistance. An important task is the development of characterization techniques for $\mathrm{SiC} / \mathrm{SiC}$ cladding, since traditional work using rectangular bars or disks cannot directly provide useful information on the properties of $\mathrm{SiC} / \mathrm{SiC}$ composite tubes for fuel cladding applications. At Oak Ridge National Laboratory, experimental capabilities are under development to characterize the modulus, microcracking, and hermeticity of as-fabricated, as-irradiated $\mathrm{SiC} / \mathrm{SiC}$ composite tubes. Resonant ultrasound spectroscopy has been validated as a promising technique to evaluate the elastic properties of $\mathrm{SiC} / \mathrm{SiC}$ composite tubes and microcracking within the material. A similar technique, impulse excitation, is efficient in determining the basic mechanical properties of $\mathrm{SiC}$ bars prepared by chemical vapor deposition; it also has potential for application in studying the mechanical properties of $\mathrm{SiC} / \mathrm{SiC}$ composite tubes. Complete evaluation of the quality of the developed coatings, a major mitigation strategy against gas permeation and hydrothermal corrosion, requires the deployment of various experimental techniques, such as scratch indentation, tensile pulling-off tests, and scanning electron microscopy. In addition, a comprehensive permeation test station is being established to assess the hermeticity of $\mathrm{SiC} / \mathrm{SiC}$ composite tubes and to determine the $\mathrm{H} / \mathrm{D} / \mathrm{He}$ permeability of $\mathrm{SiC} / \mathrm{SiC}$ composites. This report summarizes the current status of the development of these experimental capabilities.
\end{abstract}





\section{INTRODUCTION}

Silicon carbide $(\mathrm{SiC})$ has been widely applied or considered in nuclear systems as a fuel and structural material since the 1960s, given its high-temperature stability, chemical inertness, and exceptional irradiation resistance [1]. Chemical vapor-deposited (CVD) SiC has been considered as a pressure vessel material for the tristructural-isotropic (TRISO) fuel particles used in high temperature gas-cooled reactors [2]. The use of $\mathrm{SiC} / \mathrm{SiC}$ composites as primary structural materials has also been proposed in fusion reactors [3]. Recently, $\mathrm{SiC}$ has also been envisioned as a potential cladding material for light-water reactors to enhance their accident tolerance. Although high-purity $\mathrm{SiC}$ has numerous merits in comparison with Zircaloy for service in reactors, monolithic $\mathrm{SiC}$ alone has low fracture toughness. That makes it inappropriate for nuclear fuel cladding applications because a fuel cladding needs to be robust, as it is considered the first safety boundary for retaining fission products, especially under transient or off-normal conditions. The solution is to employ an engineered composite structure to address the brittle behavior, using strong $\mathrm{SiC}$ fibers reinforcing an $\mathrm{SiC}$ matrix to form an $\mathrm{SiC} / \mathrm{SiC}$ composite. The outstanding challenges to the application of this class of structural materials as fuel cladding in commercial fission reactors include defining a path toward a significant reduction in the fabrication costs, development of robust joining methods, demonstration of hermetic retention of the fission products, demonstration of hydrothermal corrosion resistance, and investigation of pellet-cladding mechanical interactions [4] [5].

Nuclear-grade $\mathrm{SiC} / \mathrm{SiC}$ composites are typically fabricated using chemical vapor infiltration (CVI), consisting of a stoichiometric and crystalline beta-phase $\mathrm{SiC}$ matrix, near-stoichiometric crystalline $\mathrm{SiC}$ fibers, and a monolayer carbon interphase or multilayer $\mathrm{C} / \mathrm{SiC}$ interphase. $\mathrm{CVI}$ is considered a lowtemperature processing method for the fabrication of $\mathrm{SiC}$ matrix composites, with the benefits of minimal process-induced damage to the fibers and reduced residual thermal stress [6]. However, CVI composites inherently consist of fabric layup architectures made up of small, elongated inter-fiber pores with more macroscopic inter-bundle pores. The porosities of as-fabricated CVI SiC/SiC composites are usually in the range of $15 \sim 20 \%$, and it is challenging to reach very low porosity levels. Therefore, a CVD coating is typically applied inside and/or outside the cladding, depending on the material design, to provide the required gas tightness. Although $\mathrm{SiC} / \mathrm{SiC}$ composites undergo pseudo-ductile facture rather than brittle failure, extensive microcracking occurs during the process, which can lead to a loss of hermeticity. Therefore, it is important to understand the relationship between microcracking behavior and the hermeticity of these $\mathrm{SiC} / \mathrm{SiC}$ composite tubes. Another challenge to the feasibility of $\mathrm{SiC} / \mathrm{SiC}$ composite cladding is the hydrothermal corrosion of $\mathrm{SiC}$ in a reactor coolant environment [7]. A thermodynamic driving force always exists to cause the silicon in $\mathrm{SiC}$ to undergo oxidation and produce silica, which readily dissolves in water. Therefore, a loss of cladding thickness is expected, imposing challenges to safety. As a consequence, the composite alone may not be sufficient to contain fission gases within the fuel cladding. Therefore, an impermeable fission gas barrier with improved hydrothermal corrosion resistance on the surface of the composite tubes is necessary, and a coating could be a solution.

The continuous fiber $\mathrm{SiC} / \mathrm{SiC}$ composite cladding must meet a range of material property and performance requirements to fulfill the "drop-in replacement" objective of the Department of Energy (DOE) related to the development of accident-tolerant fuel cladding. The implementation of $\mathrm{SiC} / \mathrm{SiC}$ composite cladding in light-water reactors requires a thorough understanding and characterization of the composite cladding produced. Although various properties of nuclear-grade $\mathrm{SiC} / \mathrm{SiC}$ composites have previously been evaluated, tube specimens were generally not used in those studies. Most of the work used rectangular bars and disk specimens for thermo-mechanical and physical property evaluations. For the evaluation of ceramic composite tubes, ASTM standard test methods are currently available for tensile tests along the tube length direction (ASTM C1773-13), hoop stress tests (ASTM 1819-15), and others. In addition, a thermal conductivity evaluation of $\mathrm{SiC} / \mathrm{SiC}$ composite tubes has been conducted by Zhang et 
al. [8]. A strength investigation of the end-plug joint sections of $\mathrm{SiC} / \mathrm{SiC}$ composite tubes was reported by Khalifa et al. [9], and helium leak rate measurement of an $\mathrm{SiC} / \mathrm{SiC}$ tube has been demonstrated by Deck et al. [10]. However, experimental capabilities are still lacking for the evaluation of some important properties of $\mathrm{SiC} / \mathrm{SiC}$ composite tubes before and after neutron exposure, including modulus, microcracking, hermeticity, and performance of the environmental barrier coating.

This report is focused on the development of experimental capabilities to investigate the modulus, microcracking, and hemeticity of pristine and coated $\mathrm{SiC} / \mathrm{SiC}$ composite tubes under unirradiated and irradiated conditions. The research was initiated under the DOE Fuel Cycle Research and Development (FCRD) program. Section 2 focuses on the introduction of two nondestructive techniques - resonant ultrasound spectroscopy and impulse excitation - to evaluate the elastic properties and microcracking of $\mathrm{SiC} / \mathrm{SiC}$ composite tubes. Section 3 includes a general introduction of characterization techniques for evaluating the quality of the coatings. Section 4 is a brief introduction of a permeation test station being developed, which is expected to assess the hermeticity of $\mathrm{SiC} / \mathrm{SiC}$ composite tubes and determine the hydrogen isotope permeability of SiC.

\section{EVALUATION OF ELASTIC PROPERTIES OF SIC/SIC COMPOSITE TUBES}

SiC-based ceramic composite cladding is an accident-tolerant fuel cladding concept being studied at Oak Ridge National Laboratory (ORNL) and elsewhere. Deployment of SiC-based cladding in fission reactors will require extensive evaluation and assessment of the mechanical properties. Although the elastic modulus can be determined with mechanical tests such as tensile testing and three-point and four-point bending flexural tests, a major drawback of these destructive tests is that the specimens are destroyed after testing. Nondestructive modulus evaluation enables us to understand the relationship between the mechanical properties and other physical properties, which is highly useful for cladding development. This section introduces two nondestructive techniques, (1) resonant ultrasound spectroscopy (RUS) and (2) impulse excitation, and their implementation for evaluating the elastic properties of SiC specimens. Since the occurrence of microcracking in a specimen will alter its bulk elastic properties, these techniques are capable of determining the occurrence of microcracking.

\subsection{RESONANT ULTRASOUND SPECTROSCOPY}

\subsubsection{Introduction}

The RUS technique is based on extracting the resonance frequencies of a specimen. Since the resonance frequencies (also called natural frequencies) depend on the size, shape, mass, and elastic stiffness of the material of the specimen, the elastic stiffness can be evaluated from the specimen's resonance frequencies. In addition, a deviation in the resonance frequency spectrum from its typical characteristics can be used to detect defects or changes in the elastic properties of the specimen. A major advantage of this technique is that it can also determine the elastic properties of anisotropic materials. Figure 1 shows a schematic of an RUS system setup. 


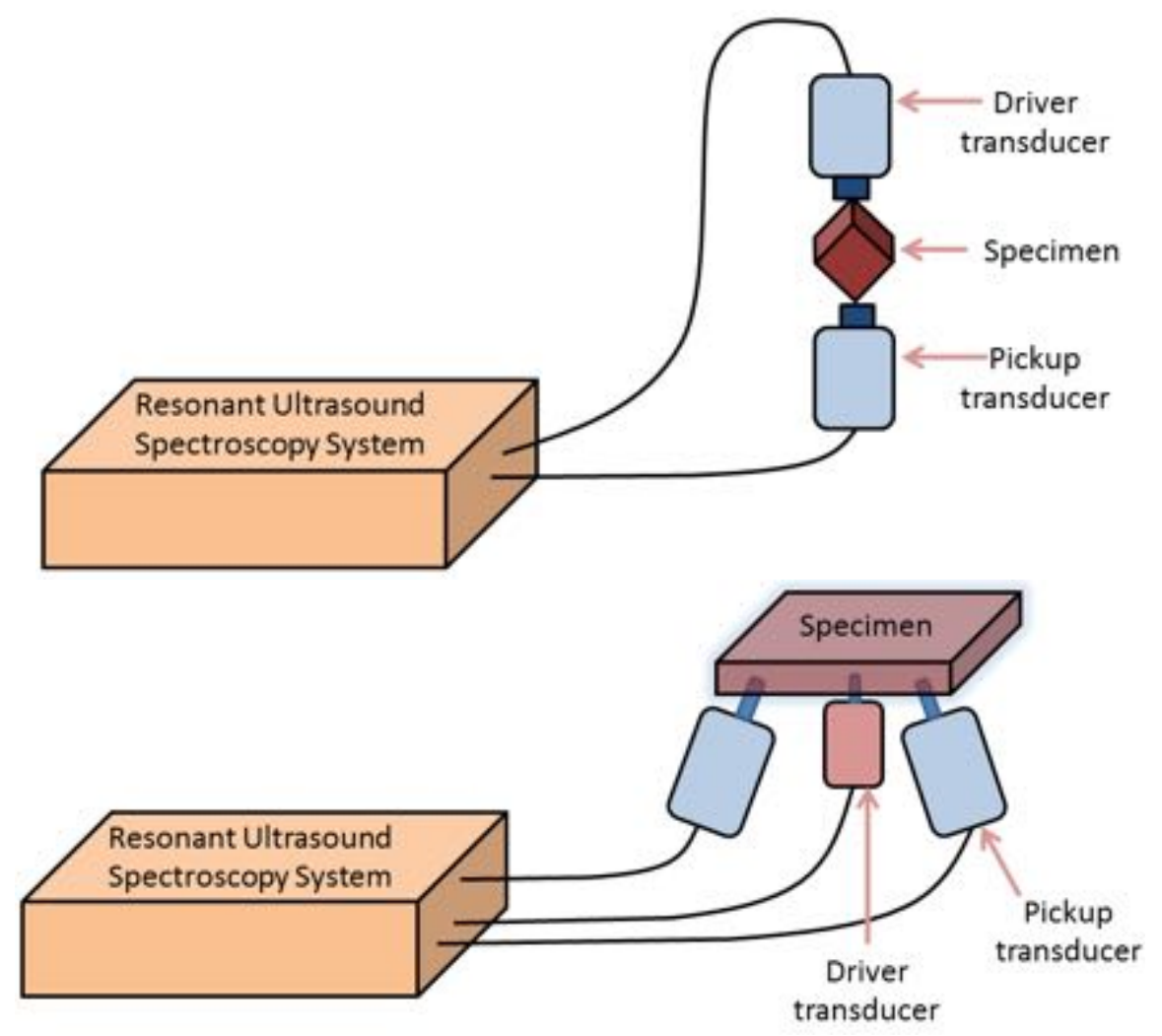

Figure 1. Schematic set up of RUS.

The origin of RUS can be traced to the 1960s, when Fraser and LeCraw [11] of Bell Telephone Laboratories (now Nokia Bell Labs) successfully determined the Lamé constant and Poisson's ratio of several materials using a shear mode transducer. This technique was then called the resonant sphere technique and was used for determining the elastic properties of geological samples [12, 13]. In the 1990s, Migliori and others researchers applied this technique to determine the elastic properties of several materials and detect defects [14-19]. With the rapid advancement of computing technology, the capability of RUS also increased. The technique has been applied to determine the elastic constants of anisotropic materials [20-23].

The resonance frequencies of a body are the same as the stationary points of a Lagrangian function [17]. Therefore, resonance frequencies of a specimen with known dimensions and elastic constants can be calculated by the Lagrangian minimization technique.

The Lagrangian of a free body is given as

where

$$
L=\iiint_{V}\left(\frac{1}{2} \rho v^{2}-\frac{1}{2} \varepsilon_{i j} C_{i j k l} \varepsilon_{k l}\right) d V
$$

$v \quad: \quad$ spatial velocity of infinitesimal element,

$\rho \quad$ : $\quad$ mass density,

$\varepsilon_{i j} \quad: \quad$ strain tensor component,

$C_{i j k l}$ : $\quad$ elastic stiffness tensor component,

$d V \quad: \quad$ infinitesimal volume,

$V \quad: \quad$ total volume 
In Eq. (2.1), the first term represents the kinetic energy and the second term represents the potential energy of the infinitesimal section of the body. The velocity term can be written as $v^{2}=\omega u^{2}=\omega u_{i} u_{i}$, where $u_{i}$ is the displacement vector component. The strain tensor component $\varepsilon_{i j}$ can be expressed as

$$
\varepsilon_{i j}=\frac{1}{2}\left(\frac{\partial u_{i}}{\partial x_{j}}+\frac{\partial u_{j}}{\partial x_{i}}\right),
$$

where $x_{j}$ is the $j^{\text {th }}$ component of the position vector. With these substitutions for velocity term and strain tensor, the Lagrangian is expressed as

$$
L=\iiint_{V}\left(\frac{1}{2} \rho \omega^{2} u_{j} u_{j}-\frac{1}{4}\left(\frac{\partial u_{i}}{\partial x_{j}}+\frac{\partial u_{j}}{\partial x_{i}}\right) C_{i j k l}\left(\frac{\partial u_{k}}{\partial x_{1}}+\frac{\partial u_{l}}{\partial x_{k}}\right)\right) d V
$$

The displacements $u_{j}$, which minimize the Lagrangian, give the natural modes of vibration of the body. There are analytical solutions for a very few geometries, such as a solid cylinder, rectangular parallelepiped, and sphere. Therefore, in most cases, the approximate solution must be obtained by numerical methods. Rayleigh-Ritz methods are commonly employed for this purpose. The Rayleigh-Ritz method involves expanding the displacement component $u_{i}$ in a set of basis functions selected according to the geometry of the body and simplifying. The resulting equation is of the form of a typical eigenvalue problem:

$$
\rho \omega^{2} I \boldsymbol{a}=\boldsymbol{\Gamma} \boldsymbol{a},
$$

where $I$ is the identity matrix, $\boldsymbol{a}$ is the eigenvector, and $\boldsymbol{\Gamma}$ is the potential energy expressed using the basis functions. The equation is solved for $\omega$, which is the resonance frequency, and the eigenvector $\boldsymbol{a}$, which corresponds to the mode of vibration.

\subsubsection{Materials and test methods}

RUS was used to determine the Young's modulus of 11 CVD SiC tube specimens; one of the specimens is shown in Figure 2. The specimens had nominal outer diameter of $8.5 \mathrm{~mm}$, inner diameter of $7.1 \mathrm{~mm}$, and length of $16.0 \mathrm{~mm}$. The mass of the specimens was about $0.885 \mathrm{~g}$. The specimens were obtained from Dow Corning.

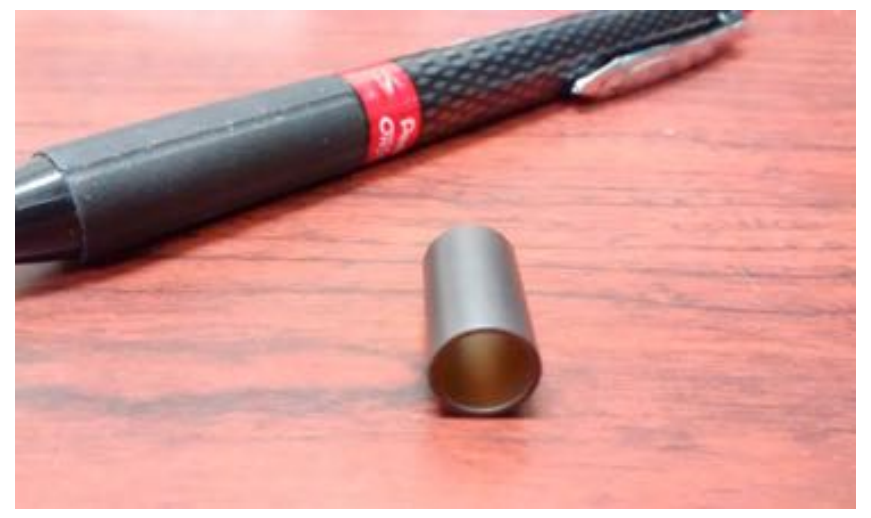

Figure 2. A CVD SiC tube specimen.

The resonance frequencies for the specimens were measured using a Magnaflux Resonant Ultrasound Spectroscopy System ${ }^{\mathrm{TM}}$ (Magnaflux Quasar, ITW Magnaflux, Glenview, IL). The RUS setup and frequency spectrum for one of the specimens are shown in Figure 3. 

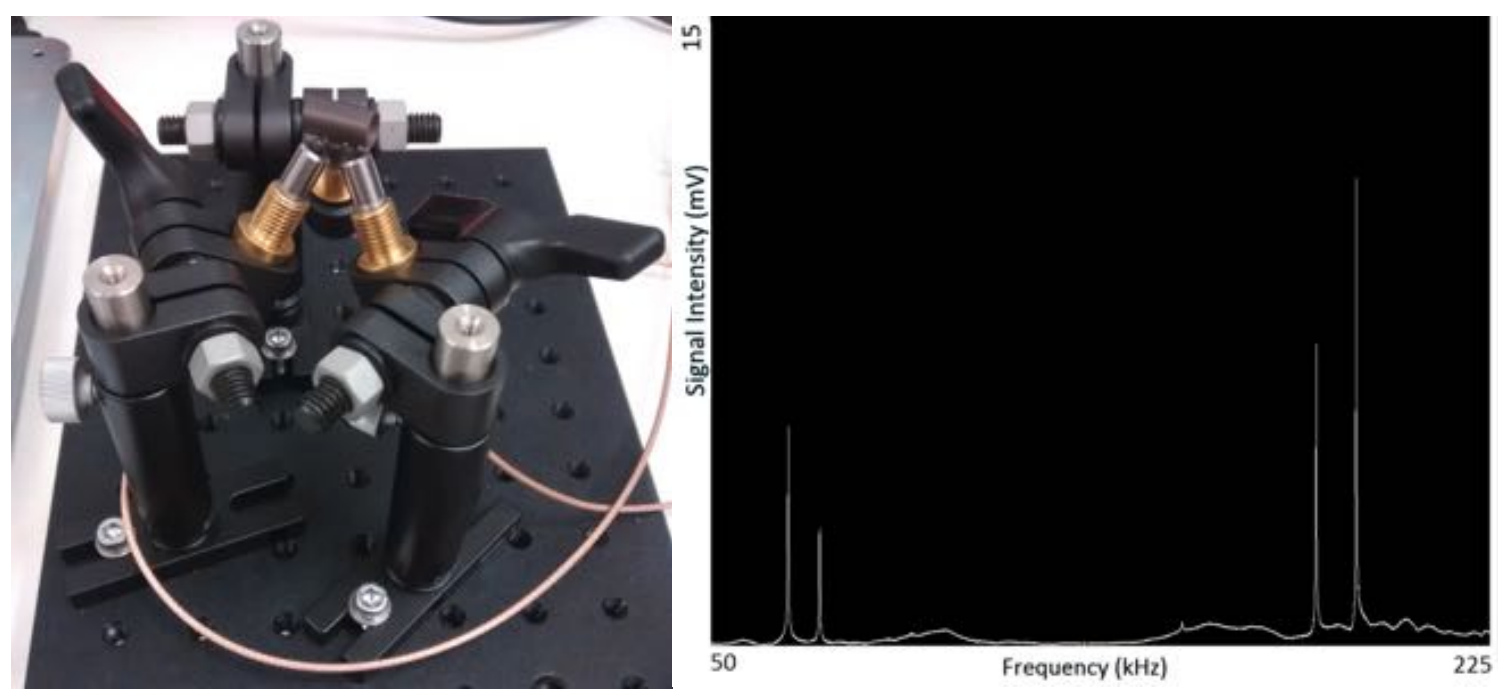

Figure 3. Specimen placed on the RUS transducers to obtain the spectrum (left). Frequency spectrum of a specimen (right).

The resonance frequencies were obtained numerically through model analysis using the commercial finite element software Abaqus [24]. The finite element (FE) model was meshed with 28,480 C3D8 (continuum 3-dimensional 8-node linear isoparametric) elements as shown in Figure 4.

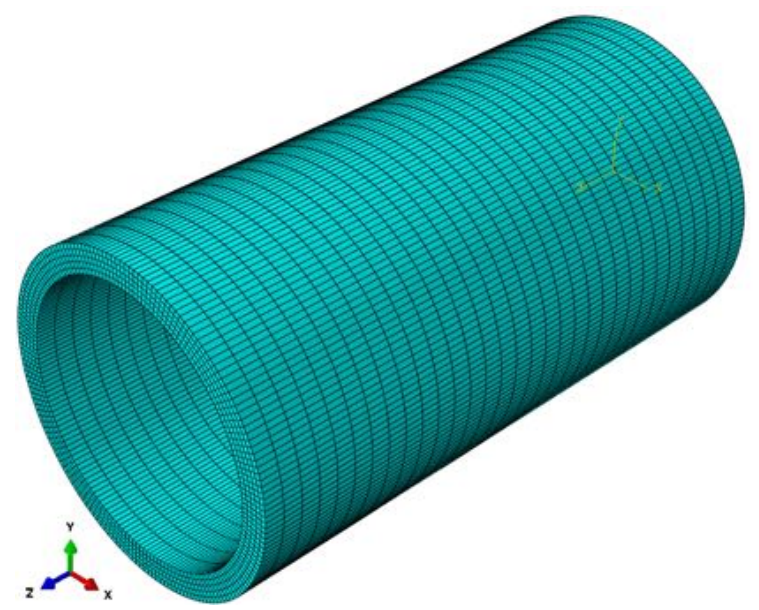

Figure 4. Finite element model of tube specimen for determining the resonance frequencies numerically.

The Poisson's ratio for the CVD SiC was set as 0.21 . The Young's modulus, being the unknown property, was allowed to vary in the expected range. The Block Lanczos iterative algorithm was used to extract the eigenvalues and eigenvectors during the analysis. For each specimen, FE analysis was performed for different trial values of Young's modulus, the numerically obtained resonance frequencies were compared with the frequencies obtained from the RUS technique, and the error was calculated as

$$
E=\sum_{i} w_{i}\left(\frac{f_{i}-g_{i}}{g_{i}}\right)^{2}
$$

where $\mathrm{w}_{\mathrm{i}}$ is the error weight for $\mathrm{i}^{\text {th }}$ mode frequency; $\mathrm{f}_{\mathrm{i}}$ is the $\mathrm{i}^{\text {th }}$ mode frequency calculated numerically; $\mathrm{g}_{\mathrm{i}}$ is the $\mathrm{i}^{\text {th }}$ mode frequency measured by RUS system. 

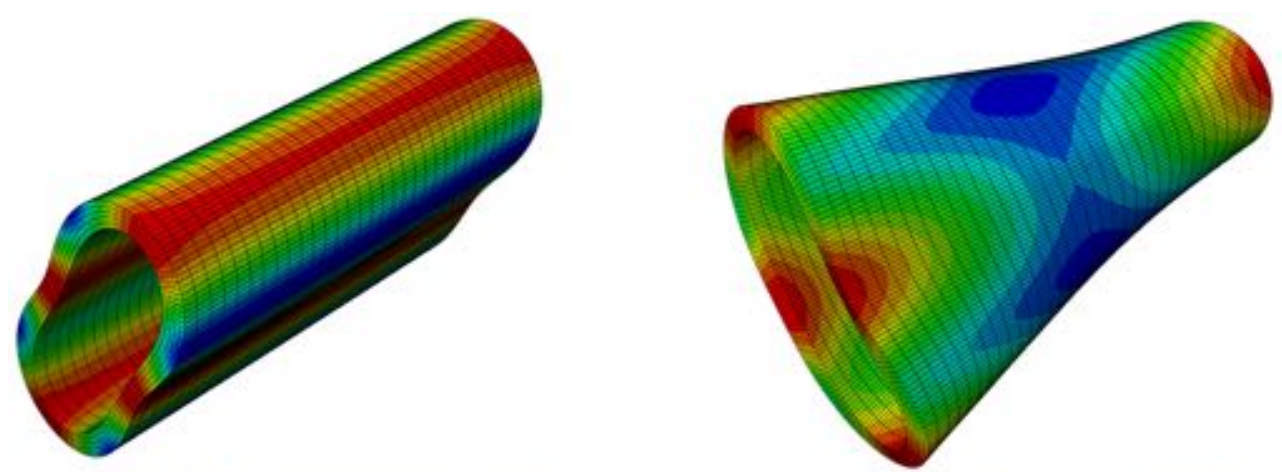

Mode 1 Frequency $=67 \mathrm{kHz}$

Mode 3 Frequency $=75 \mathrm{kHz}$
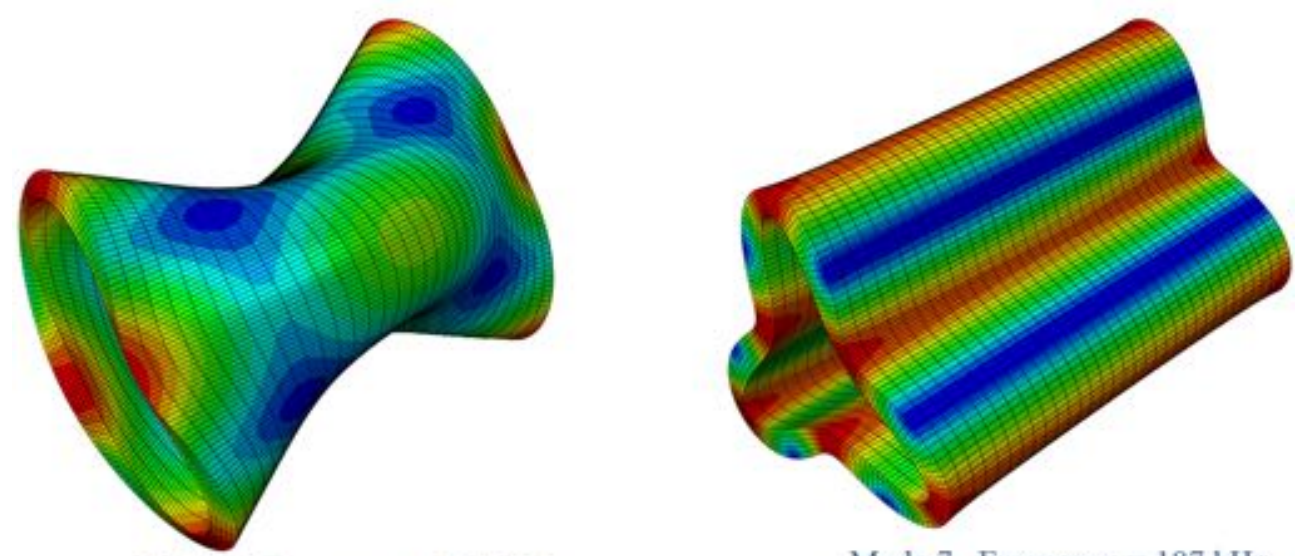

Mode 5 Frequency $=154 \mathrm{kHz}$

Mode 7 Frequency $=187 \mathrm{kHz}$
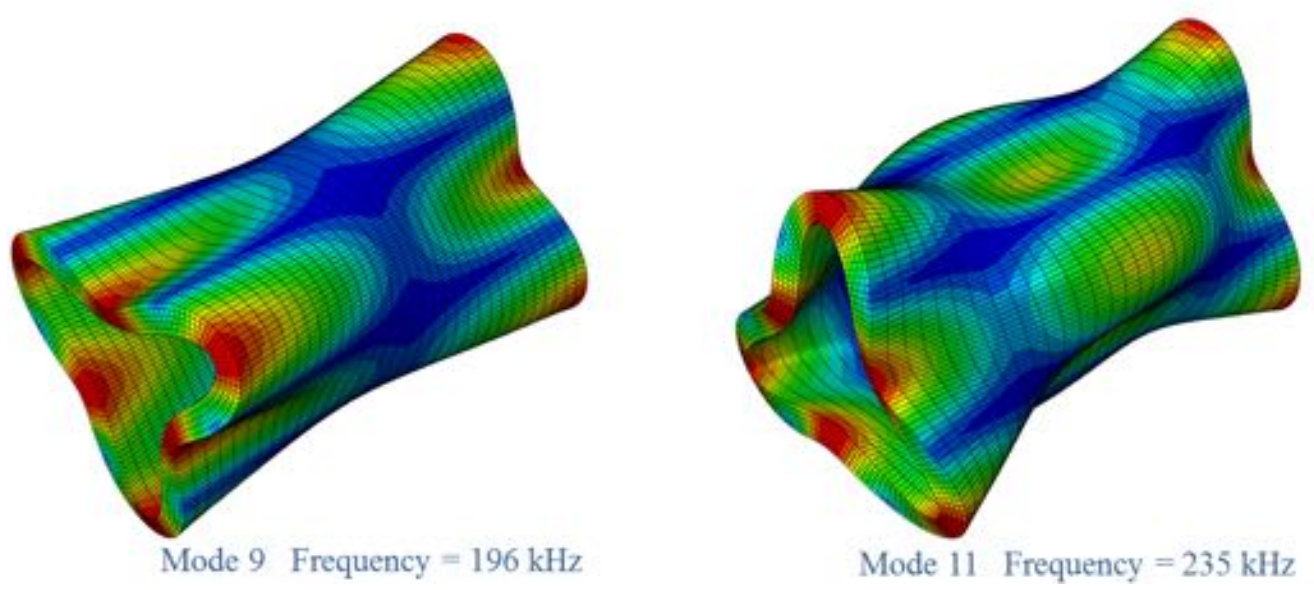

Figure 5. Numerically obtained vibration modes for a CVD SiC tube specimen.

The commercial software Isight [25] was employed for iterating the trial Young's modulus and calculating the error. Figure 5 shows different modes of vibration. Figure 6 shows the error as a function of a trial Young's modulus for a particular tube specimen. The trial Young's modulus that gave the least error was selected as the Young's modulus for the specimen. 


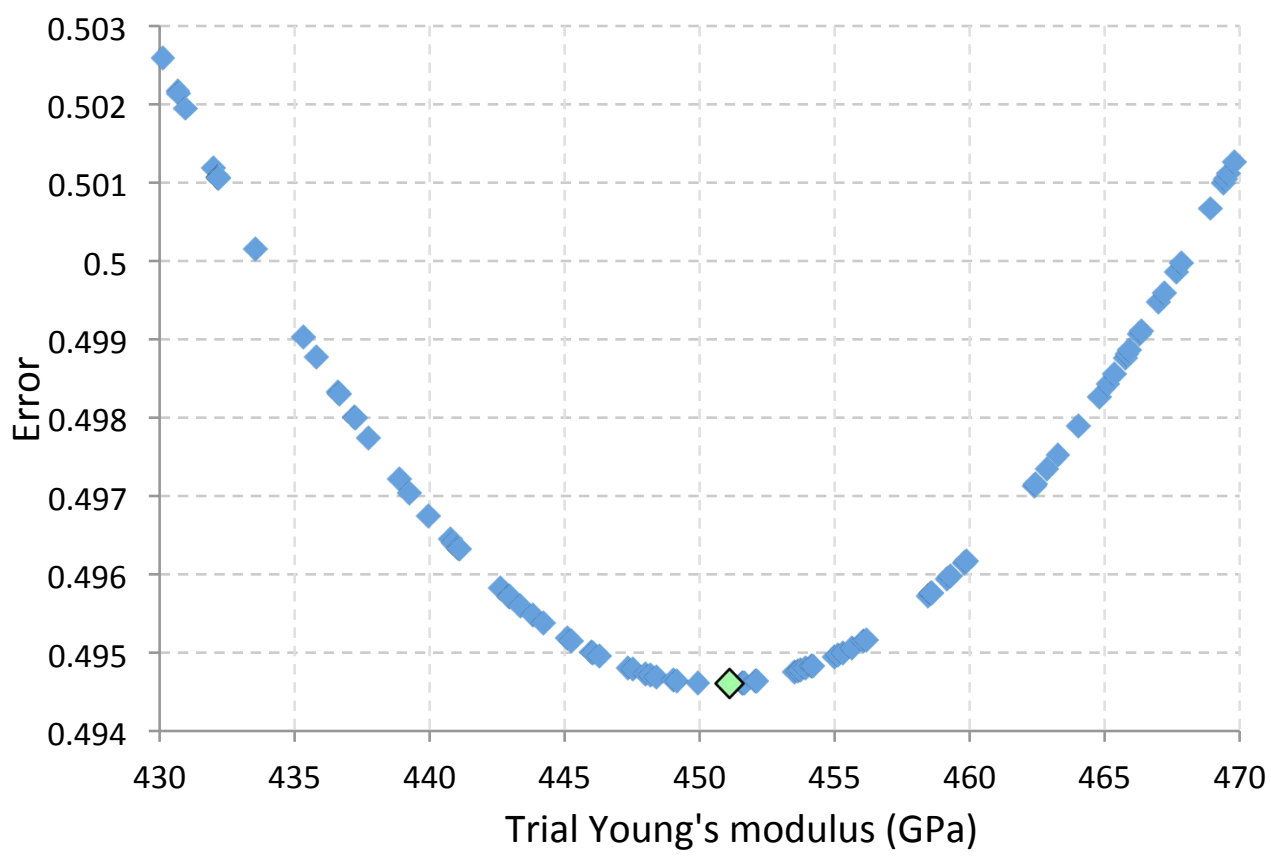

Figure 6. The cumulative difference between the numerically obtained frequencies and the frequencies obtained through RUS is denoted on the chart as "Error." The graph shows Error as a function of the Young's modulus. The green marker shows the Young's modulus that gives the best fit of the frequencies.

\subsubsection{Results}

Eleven CVD SiC specimens were used to assess the viability of RUS as a nondestructive technique to evaluate the properties of tubular SiC specimens. Table 1 shows the Young's modulus obtained for each of the specimens. Five spectra were obtained from each specimen. The average Young's modulus for all the specimens is $448.4 \mathrm{GPa}$, and the standard deviation is $3.6 \mathrm{GPa}$. The Young's modulus values are very close to the generally reported values in the literature: $450-460 \mathrm{GPa}$. Thus, RUS is a promising technique for evaluating the mechanical properties of $\mathrm{SiC}$ tubular specimens nondestructively.

Table 1. Young's modulus values for CVD SiC tubular specimens evaluated using RUS

\begin{tabular}{cc}
\hline Sample & $\begin{array}{c}\text { Young's modulus } \\
(\mathrm{GPa})\end{array}$ \\
\hline 1 & 442.8 \\
2 & 445.6 \\
3 & 443.1 \\
4 & 448.8 \\
5 & 452.1 \\
6 & 449.9 \\
7 & 451.1 \\
8 & 445.3 \\
9 & 452.8 \\
10 & 451.6 \\
11 & 448.9 \\
\hline
\end{tabular}




\subsection{IMPULSE EXCITATION TECHNIQUE}

The origin of using resonance frequencies to determine mechanical properties can be traced to 1945 when Spinner and Tefft presented a method for determining the resonance frequencies and extracting the elastic modulus from these frequencies [26]. Spinner and Tefft led the research work: determining the elastic properties from the longitudinal, flexural, and torsional vibrations at room or elevated temperatures [2730]. Better equipment and advancements in computing technology have led to widespread use of this technique in various fields [31-35]. Currently, this method is used to determine the dynamic Young's modulus, dynamic shear modulus, and Poisson's ratio of elastic materials.

The impulse excitation technique is based on the same principal as RUS. The resonance frequencies depend on the geometry, mass, and elastic properties of the material. The elastic properties of a specimen can be calculated if the geometry, mass and resonance frequencies are known.

Figure 7 shows a basic setup for this technique. The impulser strikes the specimen to initialize vibrations. The vibration signals from the specimen are detected by a transducer, for example, a contact accelerometer or noncontacting microphone, which converts the acoustic signals to electrical signals. The electrical signals are processed by computer software through Fourier transformation to evaluate the frequencies of vibrations and the corresponding intensities. The fundamental resonant frequencies, geometry, and mass are used to calculate the elastic properties. The vibration modes of a specimen depend on its shape, the point of impact, and positions of the supports. For regular-shape specimens, such as disks, rods, and bars, the modes of vibration are well defined; the supports can be placed at appropriate positions to obtain the desired mode of vibration. The technique has a well-established standard procedure, ASTM E1876-15 (Standard Test Method for Dynamic Young's Modulus, Shear Modulus and Poisson's Ratio by Impulse Excitation of Vibration).

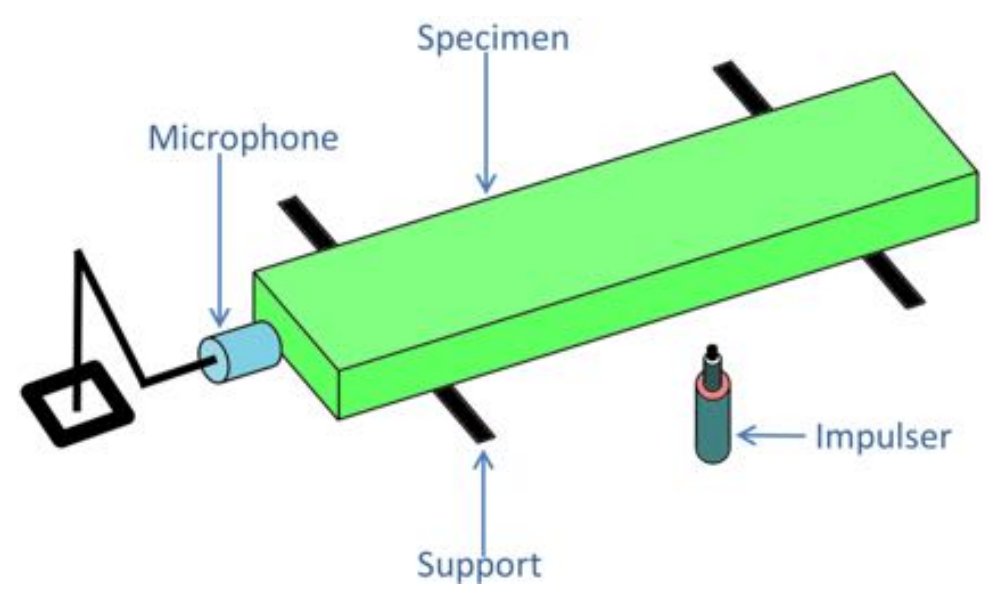

Figure 7. Schematic plot of the setup for the impulse excitation technique to determine the elastic modulus of the specimen.

\subsubsection{Materials and test methods}

Impulse excitation was used to determine the Young's modulus of three CVD SiC bar specimens. One representative specimen is shown in Figure 8. The specimens had nominal length of $46 \mathrm{~mm}$, width of $5 \mathrm{~mm}$, and thickness of $0.16 \mathrm{~mm}$. The mass of the specimens was about $0.112 \mathrm{~g}$. The specimens were obtained from Dow Corning. 


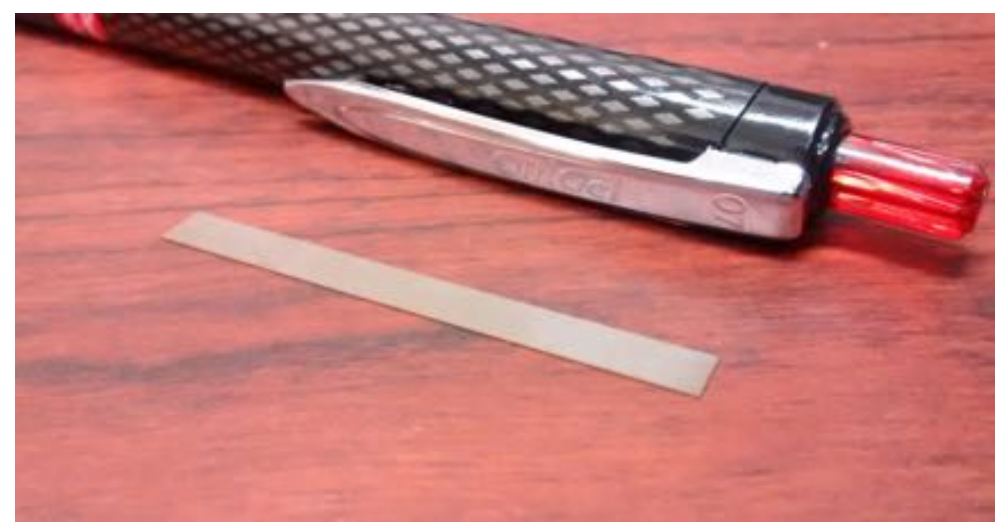

Figure 8. A CVD SiC bar specimen.

The resonance frequencies for the specimens were measured using a dedicated impulse excitation technique setup (RFDA, IMCE, Belgium), shown in Figure 9. The frequency spectrum for one of the specimens is shown in Figure 10. From the frequency spectrum, the fundamental resonant frequency is determined. The Young's modulus is obtained from the fundamental resonant frequency as

$$
E=0.9465\left(\frac{m f_{f}^{2}}{b}\right)\left(\frac{L^{3}}{t^{3}}\right) T_{1}
$$

where:

$E \quad: \quad$ dynamic Young's modulus $(\mathrm{Pa})$,

$m$ : mass of the bar $(\mathrm{g})$,

$b$ : width of the bar (mm),

$L \quad$ : length of the bar $(\mathrm{mm})$,

$t \quad: \quad$ thickness of the bar (mm),

$f_{f}:$ fundamental resonant frequency of bar in flexure $(\mathrm{Hz})$

$T_{1}$ : correction factor for fundamental flexural mode to account for finite thickness of bar, Poisson's ratio, and so on.

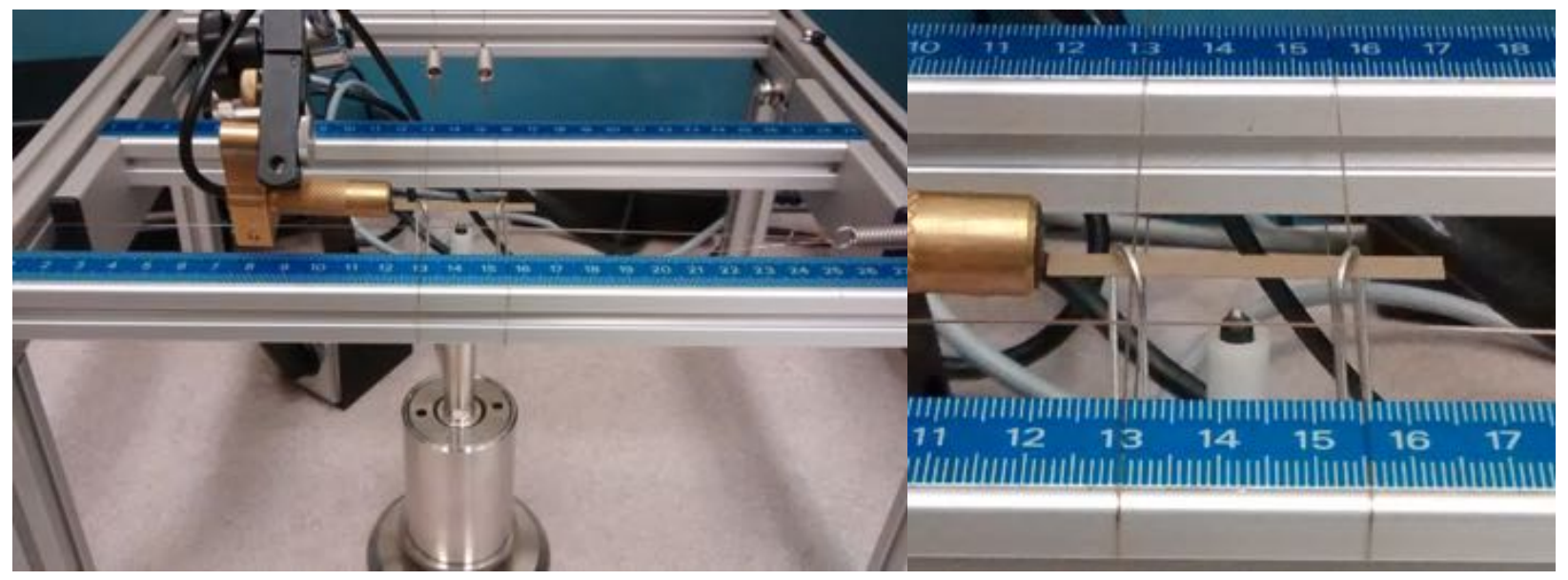

Figure 9. SiC bar specimen tested by the impulse excitation technique. 


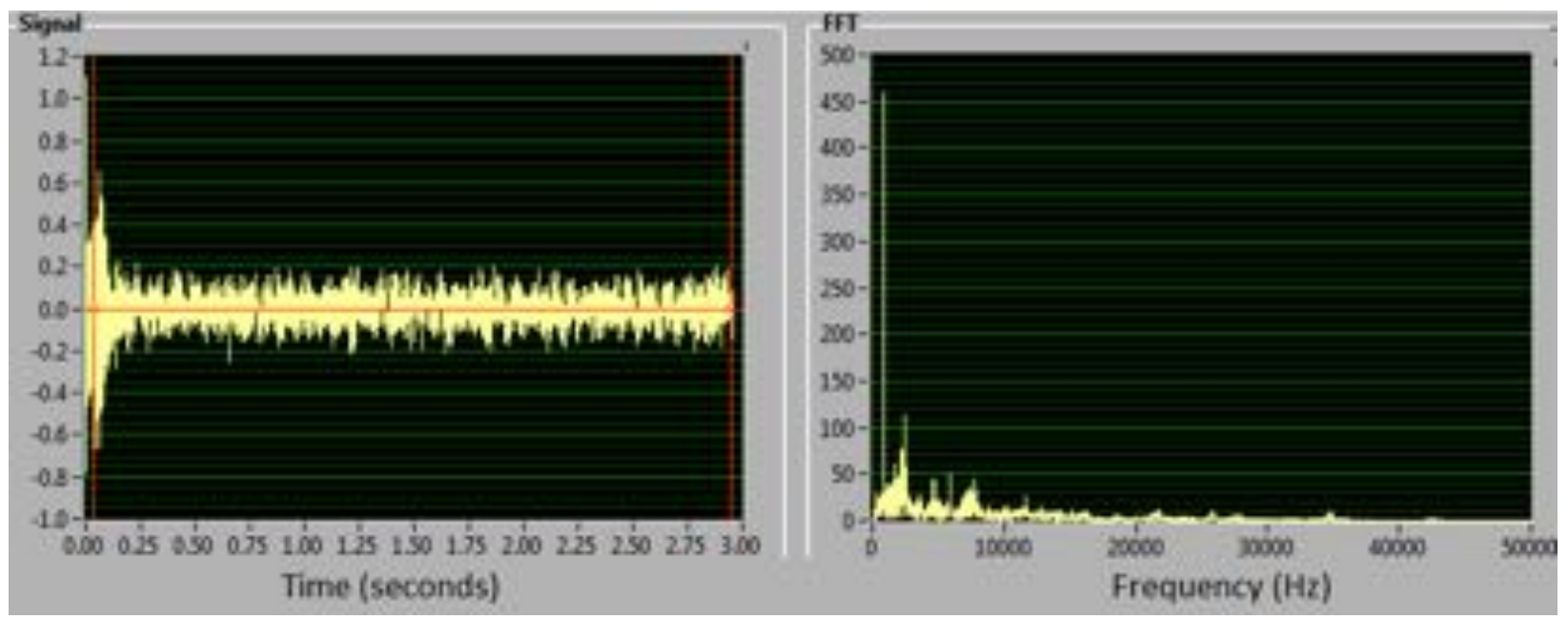

Figure 10. Signal for a specimen after conversion from acoustic to electric (left). Frequency spectrum of a specimen after Fourier fast transform (right).

\subsubsection{Results}

Three CVD SiC bar specimens were used to assess the viability of impulse excitation as a nondestructive technique to evaluate the properties of $\mathrm{SiC}$ specimens. Table 2 shows the Young's modulus values obtained for each of the specimens. The average Young's modulus for all the specimens is $442.5 \mathrm{GPa}$ and the standard deviation is $2.8 \mathrm{GPa}$. The Young's modulus values are very close to the generally reported values in the literature: $450-460 \mathrm{GPa}$. Thus, impulse excitation proved to be a promising technique for evaluating the mechanical properties of $\mathrm{SiC}$ specimens nondestructively.

Table 2. Young's modulus values for the specimens evaluated using impulse excitation

\begin{tabular}{cc}
\hline Sample & $\begin{array}{c}\text { Young's modulus } \\
(\mathrm{GPa})\end{array}$ \\
\hline 1 & 442.8 \\
2 & 445.6 \\
3 & 443.1 \\
\hline
\end{tabular}

\subsection{CORRELATION BETWEEN YOUNG'S MODULUS AND MICROCRACKING}

Figure 11 shows the stress-strain curve for an $\mathrm{SiC} / \mathrm{SiC}$ tensile test and the corresponding acoustic emission (AE) signal. The proportional limit stress marks the stress level at which significant microcracking begins in the material, as noted from the AE signal. The damage in the material leads to degradation in the material stiffness, which shows up as a decrease in the slope of the stress-strain curve or the Young's modulus. Figure 11 clearly shows that Young's modulus is associated with microcracking in the material. Since RUS and impulse excitation can evaluate the Young's modulus, these techniques have the potential to determine microcracking in the $\mathrm{SiC} / \mathrm{SiC}$ tubes. The current work will be extended to investigate the effects of microcracking on the frequency spectrum and the Young's modulus evaluated through these techniques. 

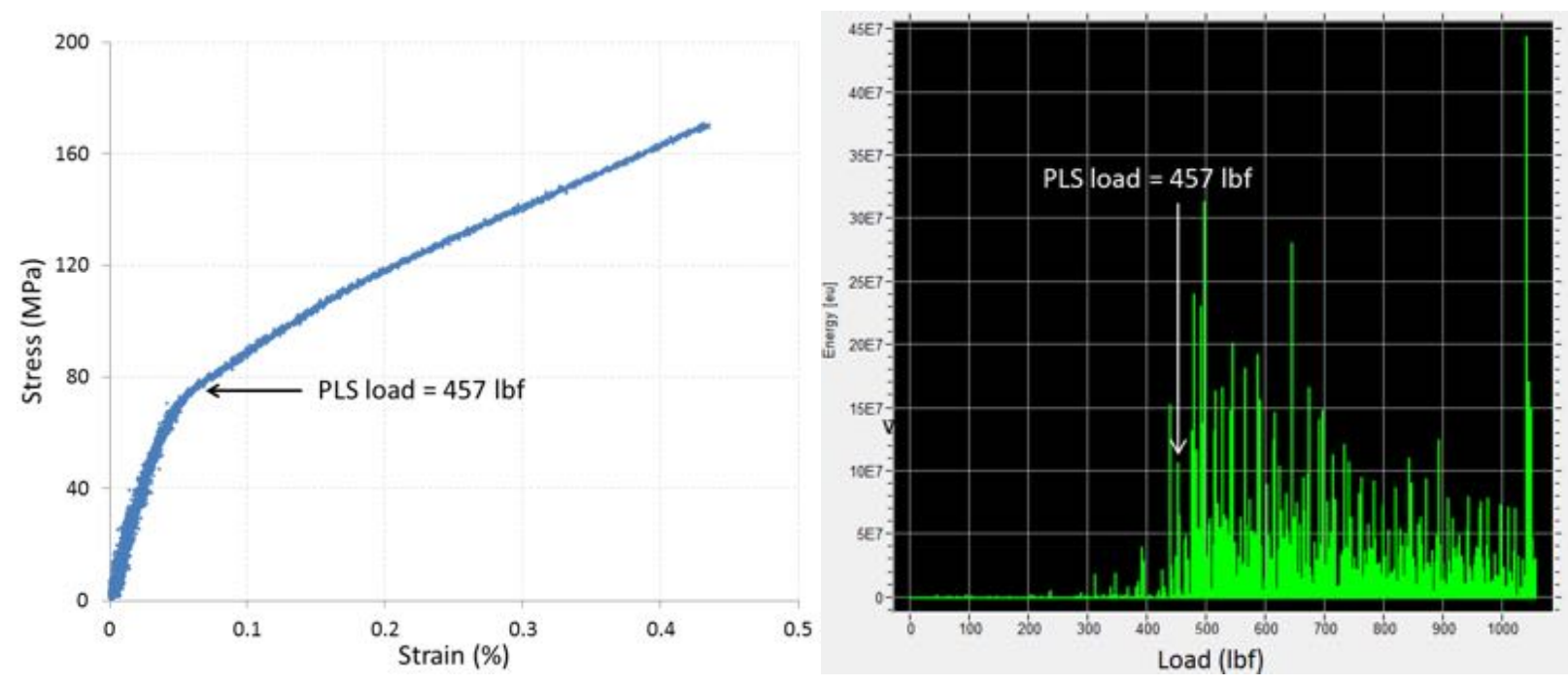

Figure 11. Stress-strain curve (left) and the corresponding acoustic emission signals (right) for a tensile test of an $\mathrm{SiC} / \mathrm{SiC}$ specimen.

\subsection{FUTURE WORK}

RUS, in conjunction with FE analysis, proved to be an efficient technique to evaluate the Young's modulus of an $\mathrm{SiC}$ tube. This technique will be applied to evaluate the mechanical properties of asfabricated and as-irradiated $\mathrm{SiC} / \mathrm{SiC}$ composite tubes in the future. The impulse excitation technique, based on a similar working principle, was applied to assess CVD SiC bars. Efforts will be made to extend this technique to determine the properties of $\mathrm{SiC} / \mathrm{SiC}$ composite tubes. The future work will focus on the evaluation of elastic properties at high temperatures. The elastic properties will include shear modulus and Poisson's ratio. In addition, this work will encompass determining the correlation among the microcracking, the consequent shift in the resonant frequencies, and the elastic properties.

\section{COATING EVALUATION}

When it is being used as a cladding material for light-water reactors, the oxidation and recession rates of bare $\mathrm{SiC} / \mathrm{SiC}$ composite cladding in an aqueous coolant environment will be unacceptable [36]. The other problem is that hermetic sealing may be difficult to achieve during normal operation [9]. These issues are complicated by the unique stresses experienced by the composite cladding; together, both hermeticity and corrosion pose serious feasibility issues. A proposed solution is a coating to serve as both an environmental barrier and a hermetic seal. The development of hermetic and robust coatings on $\mathrm{SiC}$ is being explored to address these concerns.

However, developing a coating technology is a nontrivial endeavor because of the stringent requirements. In brief, coatings must be thin and yet must satisfy the same thermophysical challenges as the substrate; a coating must accomplish its goals with very little bulk material. Significant processing challenges due to adatom deposition and substrate constraints require that a high level of confidence be attained before testing begins. For barrier coatings, imperfections in morphology are prohibited, as a single flaw can cause cladding failure. Overall, coating requires an inventive strategy, since coatings are not always meant to endure - often they are ablative, designed to recede and then be reapplied by a user. 


\subsection{DEVELOPMENT OF COATINGS ON SiC}

The coating of SiC-based cladding materials has been studied at ORNL. Since coating technologies are often independent of geometry, our coating studies have typically used $20 \times 5 \times 0.5 \mathrm{~mm}$ rectangular coupons. Since coating performance during corrosion and hermeticity tests is dependent on morphological characteristics $(\sim 100 \mu \mathrm{m}$ level $)$, the use of tubes is unnecessary at this stage. However, the use of identical materials with a characteristic "braid topology" is essential to the study of coatingsubstrate interactions for tubes, because the surface changes the processing and adhesion requirements of the coating. Typical test coupons possess a morphology of at least $500 \mu \mathrm{m}$ of nuclear-grade CVD SiC as a substrate and $2-50 \mu \mathrm{m}$ of metallic coating. In cases where tubes were used, the coating was applied on a $25 \mathrm{~mm}$ (length) by $10 \mathrm{~mm}$ (outer diameter) geometry with a $\sim 600 \mu \mathrm{m}$ wall thickness.

The substrate material was high-purity, stoichiometric CVD SiC from Rohm and Haas (now Dow Chemical Company, $\mathrm{PA}$ ) or Hi-Nicalon $\mathrm{S}$-type $\mathrm{SiC}_{\mathrm{f}}$-based fiber composites with $\mathrm{CVI} \mathrm{SiC}$ as the matrix. Nano-powder infiltration and transient eutectic-phase (NITE) SiC was also used as a nuclear-grade matrix. NITE SiC is greater than $90 \mathrm{vol} \% \mathrm{SiC}$ and uses a eutectic in the oxide fraction of the powder to densify the material. (For more information on NITE variants of SiC, see M3FT-16OR020201064, Studies on Alternative or Optimized Processing Techniques Leading to FCM Fuel Mass Production.)

For electrolytic plating, an electroless process using nickel (Ni) was first applied. The prepared SiC was inserted into palladium-based metallization solutions so that Ni could be deposited. The electroless plating of Ni occurred at a temperature of $60-80^{\circ} \mathrm{C}$. The plating rate depends on variables such as the type of plating bath, $\mathrm{pH}$, and temperature. The plating system was built around a C-MAG HS4 controlled system with a PT1000-60 feedback probe (IKA, Wilmington, NC) using a proprietary glass coating. Nickel-coated specimens were sent to industrial collaborators and vendors. The collaborator for electrolytic chromium is NEO Knoxville, LLC (Maryville, Tennessee).

For physical vapor deposition and vapor plasma spray (VPS) coatings, separate vendors were chosen based on their capability to deposit successful coatings. Prepared SiC materials were physically sent to the vendors, which carried out their proprietary processes and returned the coated specimens to ORNL for examination. For full details of the strategy, processes, and examination of the different coating morphologies and microstructures, see FCRD Level 3 Milestone (M3FT-16OR020202113), Examination of Hybrid Metal Coatings for Mitigation of Fission Product Release and Corrosion Protection of LWR $\mathrm{SiC} / \mathrm{SiC}$.

\subsection{COATING EVALUATION}

The identification of irradiation, corrosion, and processing-based damage is fundamental to understanding and overcoming challenges associated with new coatings. Detailed evaluations of the developed coatings are necessary, including both destructive and nondestructive analysis, with a primary focus on developing nondestructive screening methods for the final down-selected $\mathrm{SiC}_{\mathrm{f}}-\mathrm{SiC}$ surface and coating.

The $\mathrm{SiC}_{\mathrm{f}}$-SiC surface is not yet confirmed. It is not known yet whether the overcoating will cover the surface texture that results from braiding. If an overcoat is to be applied, then the surface is prepared by alkali etching or a graded pyrolitic carbon (PyC) interface. If the braid topology is intact, the surface can be mechanically prepared or etched. Figure 12 shows scanning electron microscope (SEM) images of the aforementioned examples and their morphologies when the chemical deposition of metals was completed. In the main image, the mechanically prepared $\mathrm{SiC}_{\mathrm{f}}-\mathrm{SiC}$ surface shows the interlocking of an electrolytic coating of Ni-Cr. The coating directly deposited from a liquid within the fiber tows. However, if there is an overcoat of dense CVD SiC material on top of the fibers, then the coating cannot infiltrate the fiber 
tows. The inset in Figure 12 shows an example of NITE SiC etched and coated. It shows that the metal coating was deposited from liquid in the grain boundaries and anchored the coating.

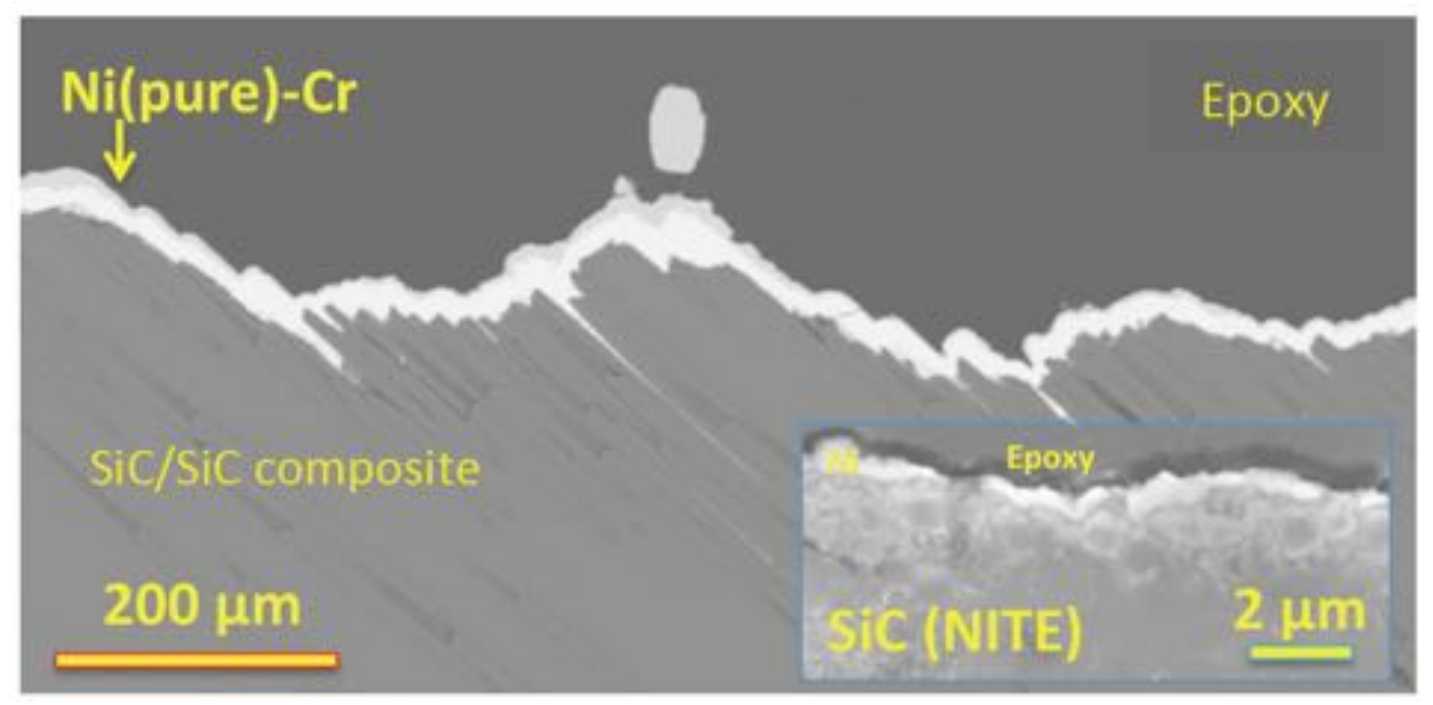

Figure 12. Two examples of braid-topologies with which a coating may interact. The main image shows exposed fiber tows on an $\mathrm{SiC}_{\mathrm{f}} \mathrm{SiC}$ surface that have been mechanically prepared. The inset on the right shows an example of the type of morphology required if an overcoat conceals the fiber tows from the coating medium.

The development of coatings is still ongoing, as various coating technologies are at different stages of maturity. Several coatings are integrated into industrial standards and immediately deployable, while others require fundamental research. An irradiation campaign is already under way for several coatings at their current stage of development. The coated SiC coupons were loaded into capsules in mid-July 2016 and inserted into the Massachusetts Institute of Technology Nuclear Research Reactor (Boston, Massachusetts) at a median temperature of $320^{\circ} \mathrm{C}$ at $5.5 \mathrm{MW}$ to determine the irradiation response. In-pile irradiations are being planned, as well as coolant exposure corrosion tests in an autoclave. Further details can be found in FCRD Level 3 Milestone (M3FT-16OR020202113), Examination of Hybrid Metal Coatings for Mitigation of Fission Product Release and Corrosion Protection of LWR SiC/SiC.

The evaluations in the next section can all be used on tubes, although they may have limits in some cases. They are included to emphasize that the use of new materials in a coating requires understanding of the coating itself and is the first stage in development before tubes are even considered. The following coating assessments are based on variable surface topologies, are generally applicable to all coatings and substrates, and can be down-selected in the future as needed.

\subsubsection{Optical microscopy}

The coatings pre- and post-irradiation were first assessed visually using a Keyence optical microscope. The materials experienced coefficient of thermal expansion mismatch and processing stresses on the order of $\sim 1 \mathrm{GPa}$, and thus failure morphologies were often very obvious (e.g., peeling and cracking). Corrosive attack often shows surface damage due to different heights during a non-uniform chemical attack or removes regions of the coating. Figure 13 shows an example optical microscopy image of an $\mathrm{SiC} / \mathrm{SiC}$ tube with a VPS coating of a zirconium-based material. 


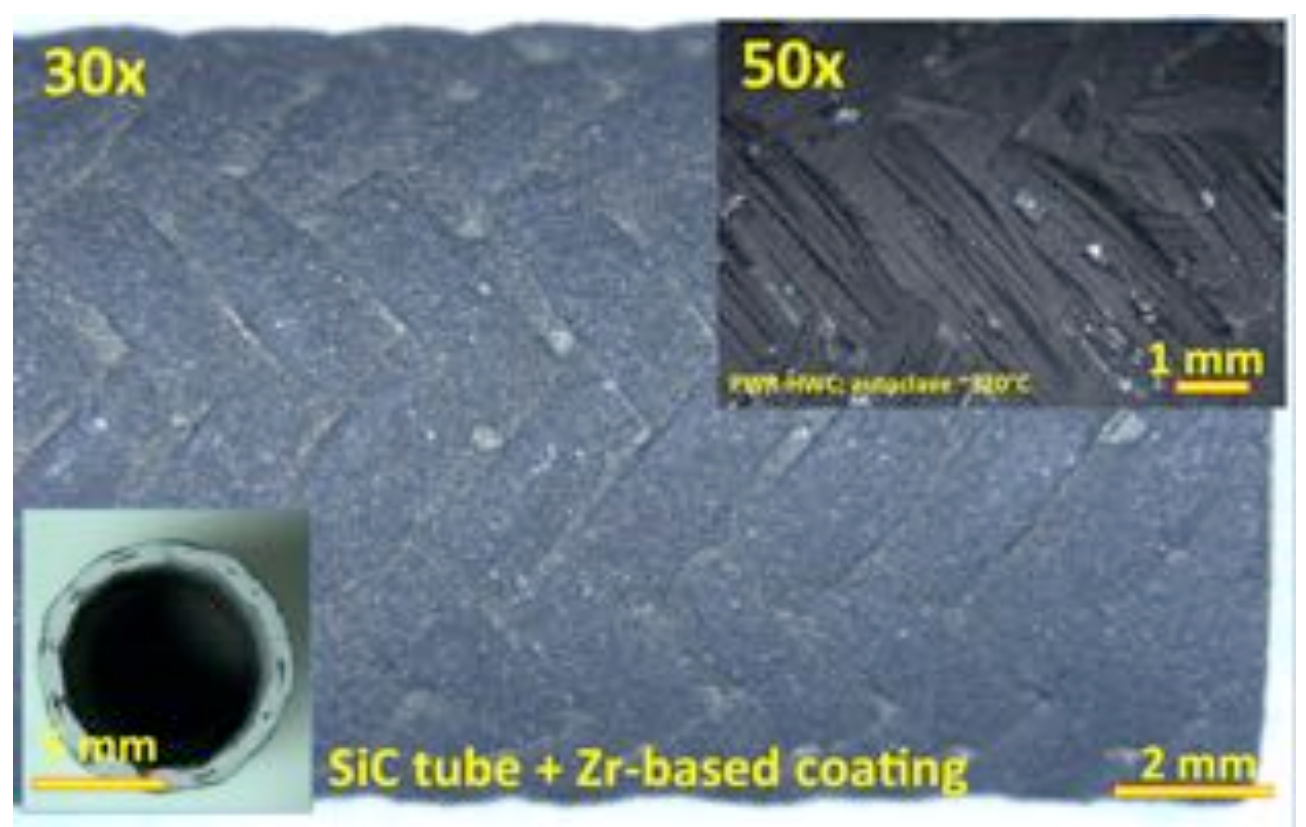

Figure 13. Main image showing the side of a $\mathrm{SiC} / \mathrm{SiC}$ tube at $30 \times$ (with an end-view shown in the inset on the lower left). The inset on the upper right shows a tube from an identical batch after exposure to reactor coolant without irradiation, showing bright regions where the coating has been attacked and removed.

VPS is a method that is relatively substrate-independent for bonding. The damage evaluation would be based on low-magnification images such as the one in Figure 13 that show different sides of the tube and includes a view from each end (inset lower left). After tubes have been irradiated or tested in corrosive media, the same regions are viewed and compared. Regions of interest—such as the inset on the top right - might be examined more closely. The inset on the top right at $50 \times$ is an example of damage after exposure in reactor coolant without irradiation, showing local recession and/or spalling of the coating.

\subsubsection{X-ray diffraction}

A baseline diffraction pattern was acquired on coatings before capsule insertion. Coatings undergo processing stresses, radiation induced-swelling, and interface stresses. The evolution of the effects on a cladding coating can be understood using microstrain, crystallite size, and unit cell lattice parameter measurements. This technique should be considered nondestructive, but it is limited to small coupons. Although it does not apply directly to tube geometries, it is expected that, during performance, the coating material must also be stable under irradiation, and this technique is part of the coating down-selection process.

\subsubsection{Electrical resistivity}

The coatings included a baseline electrical conductivity determination before capsule insertion. During irradiation, defect saturation occurs as a function of radiation dose and temperature, and an increase in electrical resistivity is expected. Quantitative data from the defect evolution during post-irradiation annealing are crucial for a fundamental understanding of these materials under irradiation. This technique should be considered as part of a nondestructive cladding evaluation and may be a useful indicator of coating quality. It can be applied to tube geometries, as the coating materials should be stable subject to irradiation. For example, it could potentially be used to determine the swelling of any coating on a tube simply by determination of the electrical resistance. 


\subsubsection{Scanning electron microscopy}

As a result of the irradiation, changes may occur to the morphologies of the phases in the coating, as well as the interface between coating and substrate. SEM cross-sections of the irradiated material and coating will improve understanding of these changes.

Figure $14 \mathrm{a}$ and $14 \mathrm{~b}$ show typical results that can provide such an analysis and can be used for tubes. The SEM image in Figure 14a shows a successfully deposited coating, and the image in 14b shows how interface failure may occur. This substrate is not CVD SiC but NITE SiC. It is used here to provide an illustration of several mechanisms that are common in all coatings under development in this program.

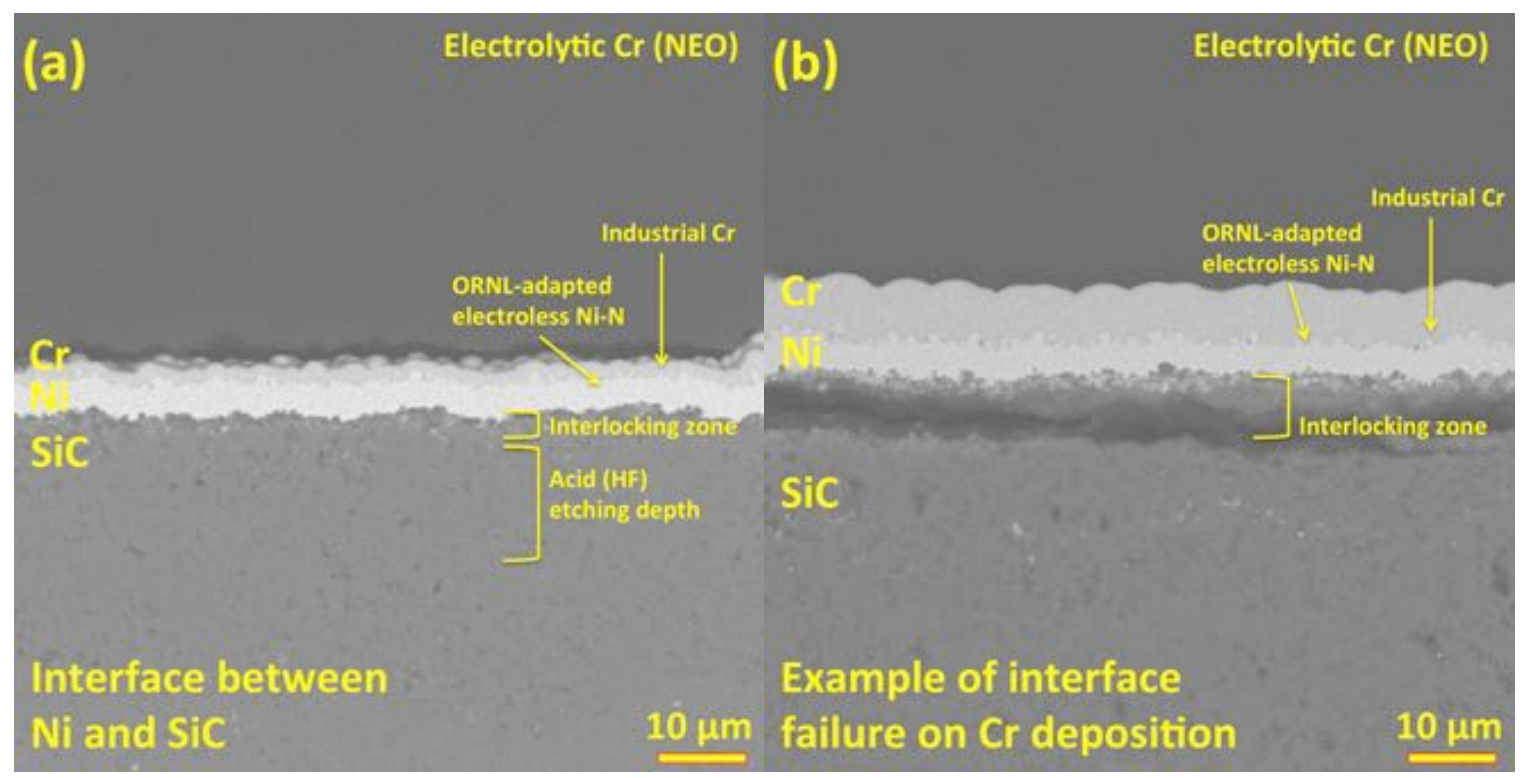

Figure 14. Polished cross-section of a coated $\mathrm{SiC}$ sample (a) that shows good interface bonding between the $\mathrm{Ni}-\mathrm{Cr}$ coating and the substrate compared with (b) a coating that shows a combination of $\mathrm{Ni}-\mathrm{SiC}$ delamination and $\mathrm{SiC}-\mathrm{SiC}$ detachment.

As an example of what information can be acquired from the cross-section, Figure 14a shows the "acid etching depth" evidenced by the porosity near the interface between coating and substrate. The dissolution of various oxides into the acid creates an "interlocking zone" as a result of the plating of $\mathrm{Ni}$ within these gaps and pores. This interlocking - along with heat treatments - is able to provide a constraint for $\mathrm{Ni}$. When chromium is deposited on the $\mathrm{Ni}$, stresses are constrained by the bonding between the $\mathrm{Ni}$ and the $\mathrm{SiC}$. This interface is usually the weakest, because the bond between Ni and chromium is strong, as is the bond between the $\mathrm{SiC}$ grains. Figure $14 \mathrm{~b}$ shows that the interface has actually failed. On visual inspection, this is often characterized by peeling. Other types of failure include tensile removal of the entire coating, which also can be visually observed. The location of the failure also may vary; in this case, the coating removal included the $\mathrm{SiC}$ substrate. This suggests good strength between the $\mathrm{SiC}$ and the $\mathrm{Ni}$ and poor bonding between $\mathrm{SiC}$ grains, probably due to the acid etching process. These morphologies seen in polished SEM cross-sections show examples of stresses and damage mechanisms found in all coatings deposited on SiC. The same methodology can be applied to tube geometries after their irradiation and autoclave testing. 


\subsubsection{Scratch indentation}

The quality of a coating can be evaluated by scratch indentation. During irradiation, the various stresses are likely to impact the interface, and scratch testing can qualitatively evaluate this change. It is also a potential simulation of the gouging process during fuel bundle insertion.

The test records two forces: the value that causes cohesion failure between regions of the coating and the force at which the coating is first removed. The method is guided strictly by ASTM E2546 but will require careful analysis owing to the unusual application of a soft coating (a metal) on a hard substrate (a ceramic). The second requirement is that the substrate be free of significant topological roughness over a $\sim 5 \mathrm{~mm}$ plane, and it is applicable only to a fully overcoated $\mathrm{SiC}_{\mathrm{f}}-\mathrm{SiC}$ composite tube. This test should provide a quantitative assessment of radiation damage of the coating-substrate interface.

In addition, the damage cross-section can be examined with 1-2 hours of focused ion beam (FIB) analysis per region of interest. Examination of multiple regions thus generates an analysis of the evolution of the damage. Figure 15 shows an example of a cross-section analysis.

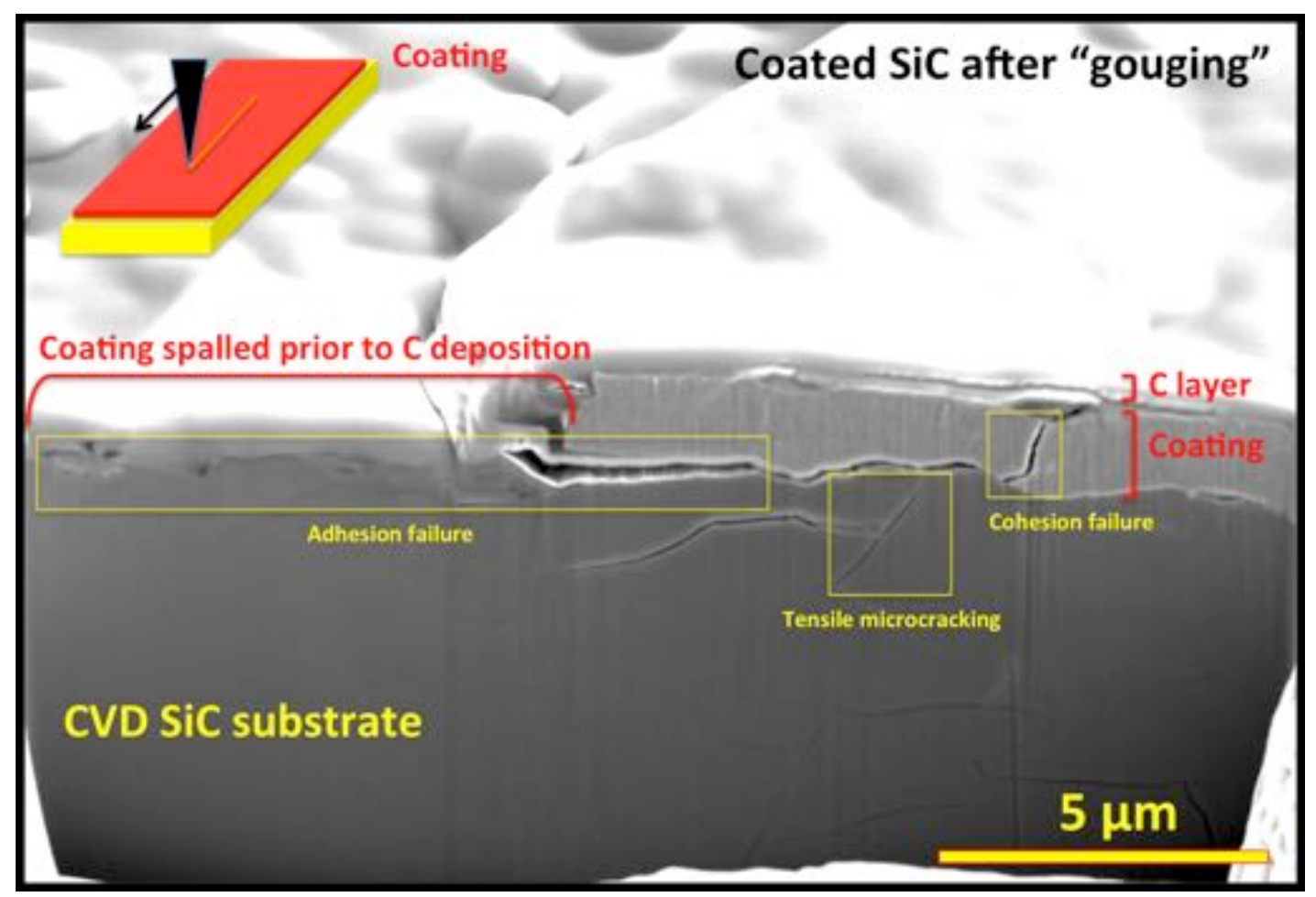

Figure 15. Cross-section of coated SiC sample after ASTM E2546 scratch indentation testing. The inset shows a schematic of a typical scratch test damaging the coating (red). After a carbon layer is added to protect against beam damage, the remaining coating can be cross-sectioned without causing additional damage that might be found from other methods (such as mechanical polishing). This particular region shows that the coating was removed in one section. Regions of identified damage are noted in boxes.

Figure 15 has an inset at the top left of a coated coupon being tested via ASTM E2546. Particular regions are selected based on either the force applied (e.g., regions where it appears the coating has spalled) or an increase in AE data (e.g., microcracking). The observed region is FIB sectioned. It provides an extremely detailed look at the damage not only to the coating but also to the substrate, which contributes to an 
understanding of how the coating interacts with the substrate under shear and compression. From an engineering standpoint, this test also provides a useful simulation of gouging events during fuel bundle insertion. Finally, this test can be fully used on coated tubes, if required, or qualitatively used on tubes that have the characteristic surface roughness seen in optical microscopy.

\subsubsection{Tensile pull-off testing}

The coatings are currently undergoing a destructive examination based on tensile pull-off tests using epoxy. During irradiation, the various stresses in the coating and substrate interact through the interface between the two phases. Testing of the strength normal to this coating-substrate plane can thus determine whether there is any effect from the irradiation. This method is not applicable to tubes but must be conducted as part of the coating development to determine substrate-interface coating interactions. Figure 16a and 16b show, respectively, the instrument parts and the modified pull-off stub used for this evaluation.
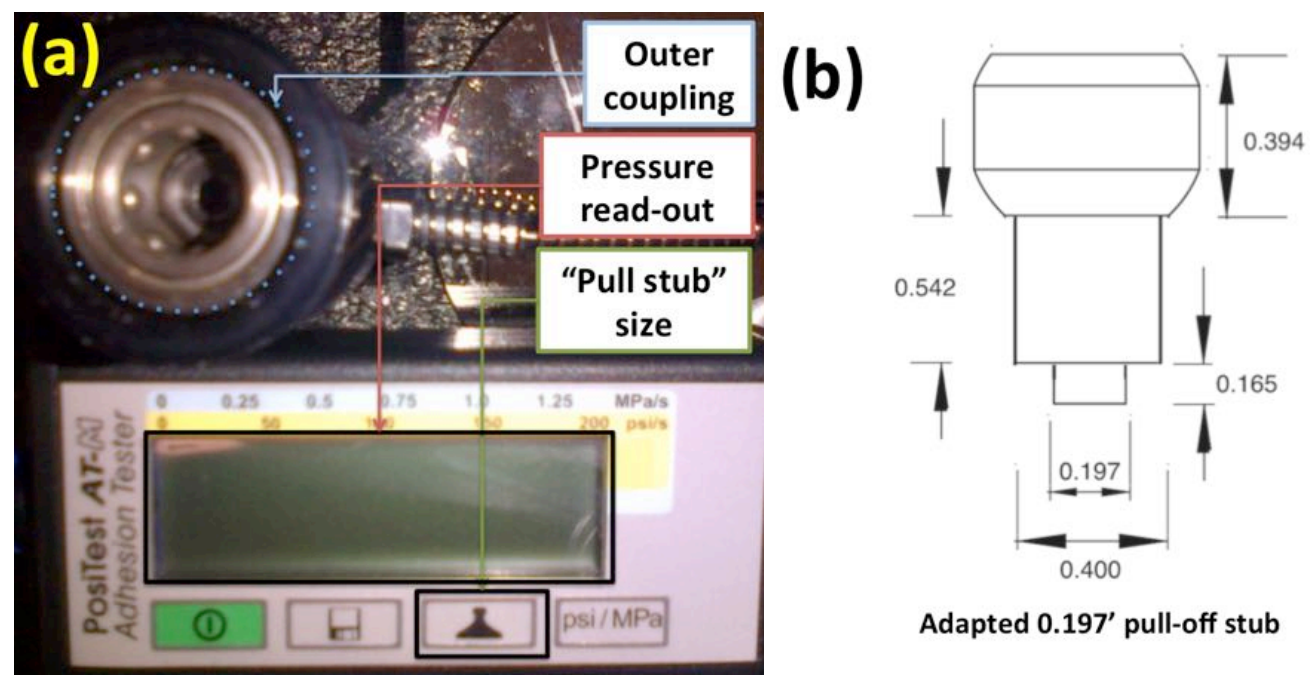

Figure 16. (a) Positest AT-M in compliance with ASTM D4541 adhesion pull-off test. The outer coupling locks around a pull stub and a pressure readout determines the pressure based on a pull-stub size setting. For the outer coupling, a modified pull stub (b) is bonded to the surface. This stub tests a region of diameter $0.197 \mathrm{in}$. or $5 \mathrm{~mm}$.

The test uses a modified ASTM D4541 system scaled down from a $10 \mathrm{~mm}$ test area to a $5 \mathrm{~mm}(0.197 \mathrm{in}$. test diameter to accommodate the small size of the irradiation coupons. Because of the deviation of the test size outside the range of the ASTM standard, this test should be considered qualitative rather than quantitative. However, it is unlikely the test can be consistently applied to tubes, and the results should be considered as data for a fundamental understanding of the adhesion strength of coated $\mathrm{SiC}$ materials. Tests are being performed on $\mathrm{SiC}_{\mathrm{f}}-\mathrm{SiC}$ plates that consist of a material and a degree of roughness comparable to those of the tubular specimens.

\subsubsection{X-ray tomography}

The coatings are being considered for x-ray tomography (XRT) because of its ability to observe $\sim 1-$ $10 \mu \mathrm{m}$ flaws in a material. Since delamination of the coating represents failure, XRT can be used to understand the morphology via a nondestructive method. However, where the substrate-coating bond appears to be intact after irradiation, XRT can evaluate whether (1) the coating is actually attached to the substrate and if so, (2) the extent of plastic deformation (e.g., delamination), without necessarily 
damaging the coating. The ultimate goal is to pursue this technique as part of a nondestructive cladding evaluation.

\subsection{FUTURE WORK}

Coatings for an $\mathrm{SiC} / \mathrm{SiC}$ composite used in coupons and tubes are being developed at ORNL, as well as the corresponding characterization capabilities. The two mechanical assessments use morphologydependent systems, and care must be taken in interpreting the data. Both scratch indentation and tensile pull-off tests characterize the quality of the coatings on flat specimens, but they may be less useful on tube specimens with different degrees of surface roughness. All other evaluations can be conducted on tubes irrespective of the roughness, coating, or surface preparation techniques. Complete evaluation of the quality of the developed coatings requires the deployment of various other experimental techniques mentioned, such as SEM and XRD. The down-selection of a successful coating and a confirmed substrate topology must occur before an evaluation methodology can be set and standardized.

\section{HERMETICITY EVALUATION}

In addition to the enhanced accident tolerance that results from using the continuous fiber $\mathrm{SiC} / \mathrm{SiC}$ composite cladding, one of the primary functions of the cladding itself is to maintain an impermeable barrier to prevent fission gas release from the fuel into the reactor primary coolants. A criterion of $\mathrm{SiC} / \mathrm{SiC}$ composite tube failure can be a loss of gas tightness. Any increase in the extent of fission gas release from the fuel will be directly proportional to the increase in the radioactivity in the primary coolant and the fission gas (e.g., tritium) release to the environment. Moreover, helium is used as the heat conduction medium between the fuel and the cladding. A loss of hermeticity would lead to the release of helium. As a consequence, the heat produced in the fuel could not efficiently taken away and the probability of fuel failure would increase. Therefore, the hermeticity of the as-fabricated and coated $\mathrm{SiC} / \mathrm{SiC}$ composite tubes and of the irradiated tubes needs to be assessed. However, there are limited data for the permeability of $\mathrm{SiC} / \mathrm{SiC}$ composites in planar and tubular configurations at elevated temperatures, especially for samples subject to neutron irradiation. We propose permeation testing to characterize the hermeticity of the $\mathrm{SiC} / \mathrm{SiC}$ composite tube by measuring the helium leakage rate. In addition, the hydrogen permeability of the $\mathrm{SiC} / \mathrm{SiC}$ composite will be identified. A comprehensive permeation station is being developed, and this preliminary report focuses on introducing the design and the technical specifications of the system.

\subsection{DEFINITION OF PERMEABILITY}

The hydrogen isotope permeability of $\mathrm{SiC}$ is an important parameter for predicting tritium release from the fuel to the primary coolant and for assessing the hermeticity of the $\mathrm{SiC} / \mathrm{SiC}$ composite tubes. The planned permeation test station is expected to capture this parameter in addition to measuring the helium leak rate. Assuming 1-dimensional transport, the flux, $J$, of hydrogen permeating through the sample can be derived from Fick's first law, assuming hydrogen solubility governed by Sieverts' law, and is given by

$$
J=\frac{D S\left(P_{i}^{1 / 2}-P_{o}^{1 / 2}\right)}{\delta}
$$

where $\delta$ is the clad wall thickness of the sample, and $P_{i}$ and $P_{o}$ are the hydrogen pressures in the upstream and downstream chambers, respectively. $P_{o}$ is negligible because the downstream chamber is always

under an ultra-high vacuum $\left(\sim 1 \times 10^{-7}\right.$ torr $)$ during measurement. The product of diffusivity, $D$, and 
Sievert's parameter, $S$, (note that $S$ is usually defined as "solubility" in hydrogen permeation studies) is defined as the permeability, $\Phi$, which can be expressed in the form of

$$
\phi=\frac{J \delta}{P_{i}^{1 / 2}}
$$

Units used here for $D$ and $S$ are, respectively, $\mathrm{m}^{2} / \mathrm{s}$ and $\mathrm{mol} \mathrm{H}_{2} / \mathrm{m}^{3} / \sqrt{\mathrm{MPa}}$, giving rise to the unit of $\Phi, \mathrm{mol} \mathrm{H}_{2} / \mathrm{m} / \mathrm{s} / \sqrt{\mathrm{MPa}}$. Therefore, the measurement of the permeation flux will result in the determination of permeability.

For most materials, permeability follows an Arrhenius temperature dependence. Thus it can be expressed as

$$
\phi=\phi_{0} \exp \left(-\frac{E}{R T}\right)
$$

where $\Phi_{0}$ is the permeability constant and $E$ is an apparent activation energy for permeation (essentially the sum of activation energies for dissolution and diffusion). Measurements of the permeability at various temperatures will enable the determination of $E$ and $\Phi_{0}$. Therefore, the hydrogen permeation rate through $\mathrm{SiC} / \mathrm{SiC}$ composite tubes could be predicted.

\subsection{DESIGN OF THE PERMEATION TEST STATION}

CVD SiC is considered a good permeation barrier material. For instance, the hydrogen permeability of $\mathrm{SiC}$ at $350^{\circ} \mathrm{C}$ is $\sim 1 \times 10^{-19} \mathrm{~mol} \mathrm{H}_{2} \mathrm{~m}^{-1} \mathrm{~s}^{-2} \mathrm{MPa}^{-1 / 2}$. Therefore, the need to measure the low fluxes expected for an $\mathrm{SiC} / \mathrm{SiC}$ composite was a major consideration in the design of the high-temperature permeation test station described here. A clean background is crucial. Therefore, ultra-high vacuum (UHV) in the system is necessary. A comprehensive UHV permeation test station to capture the permeability of helium and hydrogen isotopes in the materials of interest will be established at the Low-Activation Materials Development and Analysis laboratory at ORNL. It will be dedicated to handling both unirradiated and neutron-irradiated samples.

Figure 17 shows a schematic illustration of the permeation testing system. The system consists of two major parts, i.e., the upstream section providing the testing gas and the downstream section measuring the permeating gas. These two sections are connected through a sample fixture in which the sample of interest is used as the vacuum boundary. The sample fixture is placed in a tube furnace (an electric resistance furnace). Three types of feeding gases could be used in this system, i.e., $\mathrm{He}, \mathrm{H}_{2}$, and $\mathrm{D}_{2}$. The upstream chamber is equipped with a Pfeiffer HiPace 80 turbo-drag-pump (71 1/s) in which the prevacuum is obtained by the deployment of a Varian TriScroll 600 oil-free dry scroll vacuum pump to aid in outgassing of the system. The targeted UHV level of this system is $\sim 10^{-7}$ torr. When this vacuum level is reached, the manual gate valve connecting the vacuum chamber and the turbo pump is closed. The testing gas controlled by a needle valve is then introduced into the upstream vacuum chamber. The pressure of the gas is measured by a MKS 909AR digital and analog hot cathode vacuum transducer. A constant gas pressure is expected to be attained within several seconds; this quick control reduces the measurement error of the lag time and then the effective diffusivity. Flexible bellows are used to connect the vacuum chamber and the sample fixture, which allows flexibility in exchanging the sample fixtures for various measurements. In the downstream part of the system, the same vacuum level of $\sim 10^{-7}$ torr is achieved by applying another identical pumping system. Metal valves are used where possible to further limit residual gasses in the system. When the desired vacuum level of the downstream chamber is reached, the sample 
fixture is heated by the tube furnace; the temperature of the sample fixture is monitored by a K-type thermocouple. The permeation signals in the downstream system are measured as a function of time using a quadrupole mass spectrometer that covers a mass range from 1 to $100 \mathrm{amu}$. The hydrogen isotope signals are calibrated using VTI gas leak standards. A separate VS MD15 mobile helium leak detector with a minimum detectable leak of $5 \times 10^{-12} \mathrm{~atm} \mathrm{cc} / \mathrm{sec}$ is also included to measure the extremely low helium leakage rate through the $\mathrm{SiC} / \mathrm{SiC}$ tubes, which is not captured by the measuring system for hydrogen isotopes. The major technical specifications for this system are listed in Table 3.

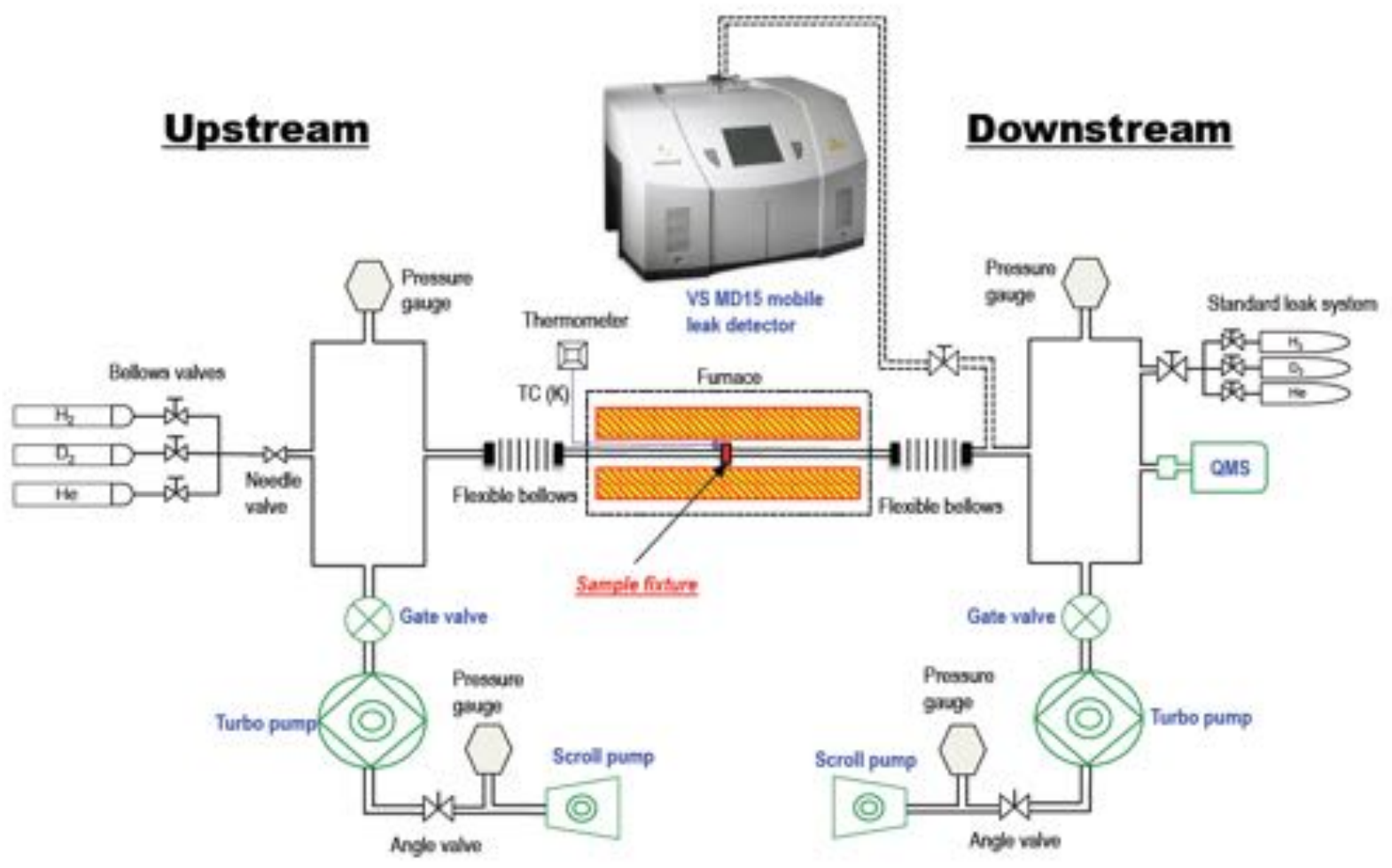

Figure 17. Schematic layout of the permeation test station.

Table 3. Major technical specifications of the permeation test station

\begin{tabular}{|c|c|c|}
\hline \multirow{2}{*}{\multicolumn{2}{|c|}{ Sample type }} & Parameter \\
\hline & & Unirradiated or neutron irradiated \\
\hline \multicolumn{2}{|l|}{ Specimen geometry } & Planar or tubular \\
\hline \multirow{2}{*}{ Size } & Planar specimen & $6 \mathrm{~mm}$ or $11 \mathrm{~mm}$ \\
\hline & Tubular specimen & $51 \mathrm{~mm}$ long and $9.5 \mathrm{~mm}$ in diameter \\
\hline \multirow{2}{*}{ Testing temperature } & Planar specimen & $\mathrm{RT} \sim 800^{\circ} \mathrm{C}$ \\
\hline & Tubular specimen & $\mathrm{RT} \sim 300^{\circ} \mathrm{C}$ \\
\hline \multicolumn{2}{|l|}{ Sample seal methods } & Mechanical seal + high temperature epoxy \\
\hline \multicolumn{2}{|l|}{ Testing gas } & $\mathrm{He}, \mathrm{H}_{2}$, and $\mathrm{D}_{2}$ \\
\hline \multicolumn{2}{|c|}{ Ultimate system pressure } & $1 \times 10^{-7}$ torr \\
\hline \multicolumn{2}{|c|}{$\begin{array}{l}\text { Pressure difference between upstream and downstream } \\
\text { during testing }\end{array}$} & $1 \mathrm{~atm}$ \\
\hline \multicolumn{2}{|c|}{ Detection limit of He leak rate } & $5 \times 10^{-12} \mathrm{~atm} \mathrm{cc} / \mathrm{sec}$ \\
\hline \multicolumn{2}{|c|}{ Detection limit of the quadrupole mass spectrometer } & $<1 \times 10^{-12}$ torr \\
\hline
\end{tabular}




\subsection{SAMPLE FIXTURES}

The hermeticity of $\mathrm{SiC} / \mathrm{SiC}$ composite tubes is represented by the helium leakage rate. The maximum allowable leakage rate for an as-manufactured light-water reactor fuel rod is $1.0 \times 10^{-6} \mathrm{~atm} \mathrm{cc} / \mathrm{sec}$ when pressurized with helium to $1.7 \mathrm{MPa}$ at room temperature. Therefore, the leakage rate requirements for the small planar and tubular specimens to be tested could be acquired by extrapolating the fuel rod leakage requirement using a linear pressure and area ratio. If a test pressure difference of $1 \mathrm{~atm}$ were assumed, a $6 \mathrm{~mm}$ planar specimen should have a $1.4 \times 10^{-11}$ atm $\mathrm{cc} / \mathrm{sec}$ leakage rate requirement; whereas the standard for a tubular specimen $9.5 \mathrm{~mm}$ in diameter and $51 \mathrm{~mm}$ in length would be $7.3 \times 10^{-10} \mathrm{~atm} \mathrm{cc} / \mathrm{sec}$ [37].

The permeability of monolithic $\mathrm{SiC}$ is extremely low, and it will be difficult to develop a specimen holding fixture that prevents helium leakage around the fixture while facilitating the measurement of very small leakage rates through the sample. General Atomics [10] has developed a sample fixture that has been verified to give consistent performance at elevated temperatures, allowing testing at $300^{\circ} \mathrm{C}$ for both planar and tubular specimens. However, the use of epoxy in this versatile sample fixture limits the maximum temperature of the testing. Therefore, we intend to have different sample fixtures for planar and tubular specimens. The use of a flexible bellows between the sample fixture and the downstream section enables convenient exchange of the different fixtures. To date, the sample fixture for planar specimens has been designed and tentatively tested using a $6 \mathrm{~mm}$ tungsten foil. Figure 18 shows the fixture for planar samples. The planar sample used as a VCR gasket is directly fixed by two VCR couplings and divides the vacuum system into two parts. The diameters of the permeation area are $2.3 \mathrm{~mm}$ and $5.6 \mathrm{~mm}$ for samples with diameters of $6 \mathrm{~mm}$ and $11 \mathrm{~mm}$, respectively. The preliminary test of this sample fixture using a high-vacuum system indicated that a good vacuum level of $8 \times 10^{-6}$ torr at room temperature and $9 \times 10^{-6}$ torr at $650^{\circ} \mathrm{C}$ could be maintained. Note that the rough surface of the planar $\mathrm{SiC} / \mathrm{SiC}$ composite specimen might require the application of a high-temperature epoxy to enhance the seal, which would limit the maximum testing temperature.

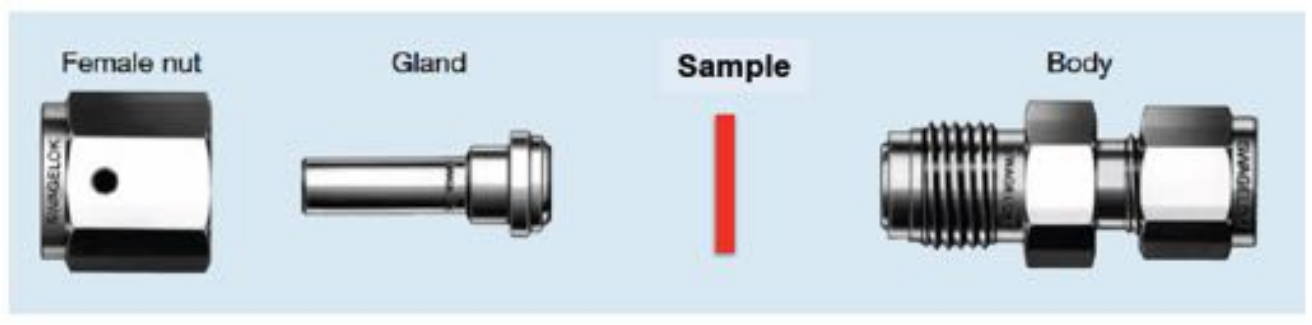

Figure 18. Planar sample fixture used in the permeation test station.

A sample fixture assembly incorporating a mechanical seal against the sample, as well as the use of hightemperature epoxy, is under development for the tubular specimens in this study. Figure 19 shows a schematic plot of the initial design of the tubular sample fixture. A stainless steel tube will be used to contain the testing specimen and separate the upstream and downstream chambers. A CF flange is used to seal the chamber, enabling frequent sample changes. Two types of tubular specimens could be used in this sample fixture: open-ended $\mathrm{SiC} / \mathrm{SiC}$ tubes, and tubes having one end sealed with an $\mathrm{SiC}$ endplug joined using an SiC-based joint. Figure 19 shows the fixture used for the samples having one sealed end. For the open-ended samples, the open end of the tube could be sealed using another set of tube fittings (i.e., female nut, male nut, ferrules). The application of high-temperature epoxy as the primary seal is an attractive option because the epoxy could conform to the rough surface of the $\mathrm{SiC} / \mathrm{SiC}$ composite tubes without a need for specialized polishing or machining. The maximum testing temperature of this sample fixture is strongly dependent on the epoxy used. 


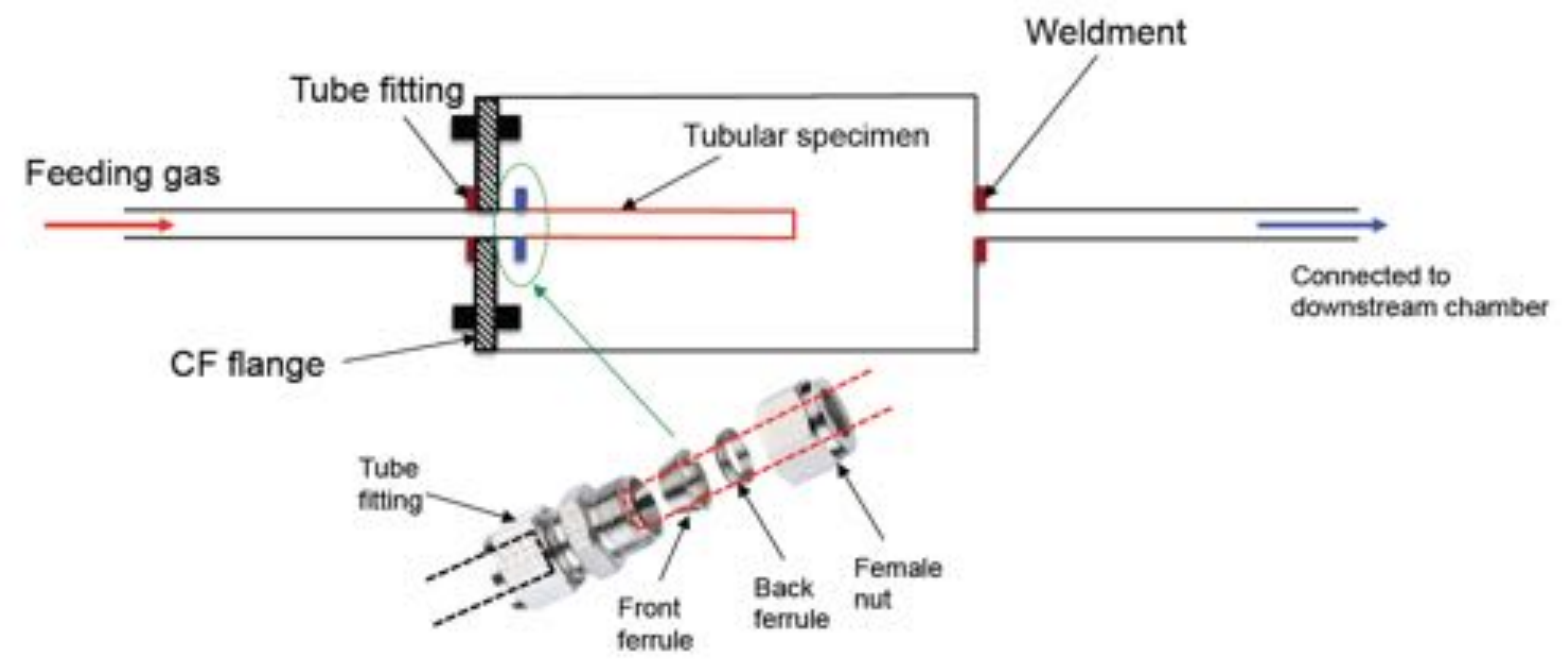

Figure 19. Schematic plot of the tubular specimen used in the permeation test station.

\subsection{FUTURE WORK}

The design and construction of the comprehensive permeation test station is ongoing. The instruments used in this system are being purchased, and the instruments highlighted in blue in Figure 17 have been delivered to ORNL. The key challenge is the design and testing of the sample fixture for tubular specimens, which will be the focus of the future work.

\section{SUMMARY}

As the complete characterization of $\mathrm{SiC} / \mathrm{SiC}$ composite tubes is crucial before they can be deployed in the nuclear power production industry, the experimental capabilities to evaluate the mechanical properties and hermeticity of as-fabricated and coated $\mathrm{SiC} / \mathrm{SiC}$ composite tubes before and after neutron irradiation are being established at ORNL. The preliminary results indicate that RUS and impulse excitation are two promising nondestructive characterization tools for measuring the elastic properties of CVD SiC tubes and bars, respectively. These two techniques are envisioned as two powerful tools to evaluate the mechanical properties of $\mathrm{SiC} / \mathrm{SiC}$ composite tubes in the future. To enhance the resistance to hydrothermal corrosion and improve the hermeticity of $\mathrm{SiC} / \mathrm{SiC}$ composite tubes, a coating is being developed. The techniques to assess the coating quality are introduced in this report. A comprehensive permeation test station is also under development to evaluate the hermeticity of the $\mathrm{SiC} / \mathrm{SiC}$ composite tubes. The preliminary efforts described herein lay a foundation for further research and development efforts to develop a robust $\mathrm{SiC} / \mathrm{SiC}$ composite cladding for nuclear applications.

\section{REFERENCES}

1. Snead, L.L., et al., Handbook of SiC properties for fuel performance modeling. Journal of Nuclear Materials, 2007. 371(1-3): p. 329-377.

2. Price, R.J., Properties of silicon carbide for nuclear fuel particle coatings. Nuclear Technology, 1977. 35: p. 320-336. 
3. Hasegawa, A., et al., Critical issues and current status of SiC/SiC composites for fusion. Journal of Nuclear Materials, 2000. 283-287: p. 128-137.

4. Zinkle, S.J., et al., Accident tolerant fuels for LWRs: A perspective. Journal of Nuclear Materials, 2014. 448(1-3): p. 374-379.

5. Katoh, Y. and K.A. Terrani, Systematic Technology Evaluation Program for SiC/SiC Compositebased Accident-Tolerant LWR Fuel Cladding and Core Structures. ORNL/TM-2015/454, 2015.

6. Katoh, Y., et al., Continuous SiC fiber, CVI SiC matrix composites for nuclear applications: Properties and irradiation effects. Journal of Nuclear Materials, 2014. 448(1-3): p. 448-476.

7. Terrani, K.A., et al., Hydrothermal corrosion of SiC in LWR coolant environments in the absence of irradiation. Journal of Nuclear Materials, 2015. 465: p. 488-498.

8. Zhang, J., et al., Thermal diffusivity measurement of curved samples using the flash method. Ceramic Materials for Energy Applications V, 2015.

9. Khalifa, H.E., et al., Fabrication and characterization of joined silicon carbide cylindrical components for nuclear applications. Journal of Nuclear Materials, 2015. 457: p. 227-240.

10. Deck, C.P., et al., Characterization of SiC-SiC composites for accident tolerant fuel cladding. Journal of Nuclear Materials, 2015. 466: p. 667-681.

11. Fraser, D. and R. LeCraw, Novel method of measuring elastic and anelastic properties of solids. Review of Scientific Instruments, 1964. 35(9): p. 1113-1115.

12. Soga, N. and O.L. Anderson, Elastic properties of tektites measured by resonant sphere technique. Journal of Geophysical Research, 1967. 72(6): p. 1733-1739.

13. Schreiber, E., et al., Sound velocity and compressibility for lunar rocks 17 and 46 and for glass spheres from the lunar soil. Science, 1970. 167(3918): p. 732-734.

14. Migliori, A., et al., Resonant ultrasound spectroscopic techniques for measurement of the elastic moduli of solids. Physica B: Condensed Matter, 1993. 183(1-2): p. 1-24.

15. Lei, M., et al., Elastic constants of a monocrystal of superconducting YBa $2 \mathrm{Cu} 3 \mathrm{O} 7-\delta$. Physical Review B, 1993. 47(10): p. 6154.

16. Migliori, A. and T.W. Darling, Resonant ultrasound spectroscopy for materials studies and nondestructive testing. Ultrasonics, 1996. 34(2): p. 473-476.

17. Migliori, A. and J.L. Sarrao, Resonant Ultrasound Spectroscopy: Applications to Physics, Materials Measurements, and Nondestructive Evaluation. 1997: Wiley-Interscience.

18. Migliori, A. and J. Maynard, Implementation of a modern resonant ultrasound spectroscopy system for the measurement of the elastic moduli of small solid specimens. Review of Scientific Instruments, 2005. 76(12): p. 121301.

19. Maynard, J. Resonant ultrasound spectroscopy. in Medical Imaging '98. 1998. International Society for Optics and Photonics.

20. Nakamura, N., et al., Determination of anisotropic elastic constants of superlattice thin films by resonant-ultrasound spectroscopy. Journal of Applied Physics, 2005. 97(1): p. 013532.

21. Kinney, J., et al., Resonant ultrasound spectroscopy measurements of the elastic constants of human dentin. Journal of Biomechanics, 2004. 37(4): p. 437-441.

22. Ichitsubo, T., et al., Anisotropic elastic constants of lotus-type porous copper: Measurements and micromechanics modeling. Acta Materialia, 2002. 50(16): p. 4105-4115.

23. Ulrich, T.J., K. McCall, and R. Guyer, Determination of elastic moduli of rock samples using resonant ultrasound spectroscopy. The Journal of the Acoustical Society of America, 2002. 111(4): p. 1667-1674.

24. SIMULIA, Dassault Systemes Simulia Corp., Providence, RI, USA.

25. Isight, Dassault Systemes Simulia Corp., Providence, RI, USA.

26. Spinner, S. and W. Tefft. A Method for Determining Mechanical Resonance Frequency and for Calculating Elastic Modulus from These Frequencies. in Proceedings of ASTM. 1945.

27. Spinner, S., T. Reichard, and W. Tefft, A comparison of experimental and theoretical relations between Young's modulus and the flexural and longitudinal resonance frequencies of uniform 
bars. Journal of Research of the National Bureau of Standards - A. Physics and Chemistry, 1960. 64(2).

28. Tefft, W.E. and S. Spinner, Torsional resonance vibrations of uniform bars of square cross section. Journal of Research of the National Bureau of Standards, 1961. 65: p. 167-171.

29. Tefft, W.E. and S. Spinner, Cross-sectional correction for computing Young's modulus from longitudinal resonance vibrations of square and cylindrical rods. Journal of Research of the National Bureau of Standards A, 1962. 66: p. 193-197.

30. Spinner, S. and A. Rozner, Elastic properties of NiTi as a function of temperature. The Journal of the Acoustical Society of America, 1966. 40(5): p. 1009-1015.

31. Roebben, G., et al., The innovative impulse excitation technique for high-temperature mechanical spectroscopy. Journal of Alloys and Compounds, 2000. 310(1): p. 284-287.

32. Roebben, G., et al., Assessment of the high temperature elastic and damping properties of silicon nitrides and carbides with the impulse excitation technique. Journal of the European Ceramic Society, 2002. 22(14): p. 2501-2509.

33. Williams, K. and A. Williams, Impulse response of a dental implant in bone by numerical analysis. Biomaterials, 1997. 18(10): p. 715-719.

34. Heritage, K., C. Frisby, and A. Wolfenden, Impulse excitation technique for dynamic flexural measurements at moderate temperature. Review of Scientific Instruments, 1988. 59(6): p. 973974.

35. Atri, R., K. Ravichandran, and S. Jha, Elastic properties of in-situ processed Ti-TiB composites measured by impulse excitation of vibration. Materials Science and Engineering: A, 1999. 271(1): p. $150-159$.

36. Terrani, K.A., et al., Hydrothermal corrosion of SiC in LWR coolant environments in the absence of irradiation. Journal of Nuclear Materials, 2015. 465: p. 488-498.

37. Gutierrez, O., et al., Permeability measurements for SiC ceramic matrix composites relevant to LWR. Transactions of the American Nuclear Society, 2014. 110: p. 803-806. 